\title{
Engineering \\ and Construction Manual for an Instrument to Make Burn Hazard Measurements In Consumer Products
}

QO

100

5753

0.816

1974

c. 2

U.S. PARTMENT OF OMMERCE National Bureau of

Standards 
The National Bureau of Standards ${ }^{1}$ was established by an act of Congress March 3, 1901. The Bureau's overall goal is to strengthen and advance the Nation's science and technology and facilitate their effective application for public benefit. To this end, the Bureau conducts research and provides: (1) a basis for the Nation's physical measurement system, (2) scientific and technological services for industry and government, (3) a technical basis for equity in trade, and (4) technical services to promote public safety. The Bureau consists of the Institute for Basic Standards, the Institute for Materials Research, the Institute for Applied Technology, the Institute for Computer Sciences and Technology, and the Office for Information Programs.

THE INSTITUTE FOR BASIC STANDARDS provides the central basis within the United States of a complete and consistent system of physical measurement; coordinates that system with measurement systems of other nations; and furnishes essential services leading to accurate and uniform physical measurements throughout the Nation's scientific community, industry, and commerce. The Institute consists of a Center for Radiation Research, an Office of Measurement Services and the following divisions:

Applied Mathematics - Electricity - Mechanics - Heat - Optical Physics - Nuclear Sciences $^{2}$ - Applied Radiation ${ }^{2}$ - Quantum Electronics ${ }^{3}$ - Electromagnetics ${ }^{3}$ - Time and Frequency * - Laboratory Astrophysics ${ }^{3}$ - Cryogenics *.

THE INSTITUTE FOR MATERIALS RESEARCH conducts materials research leading to improved methods of measurement, standards, and data on the properties of well-characterized materials needed by industry, commerce, educational institutions, and Government; provides advisory and research services to other Government agencies; and develops, produces, and distributes standard reference materials. The Institute consists of the Office of Standard Reference Materials and the following divisions:

Analytical Chemistry - Polymers - Metallurgy - Inorganic Materials — Reactor Radiation - Physical Chemistry.

THE INSTITUTE FOR APPLIED TECHNOLOGY provides technical services to promote the use of available technology and to facilitate technological innovation in industry and Government; cooperates with public and private organizations leading to the development of technological standards (including mandatory safety standards), codes and methods of test; and provides technical advice and services to Government agencies upon request. The Institute consists of a Center for Building Technology and the following divisions and offices:

Engineering and Product Standards — Weights and Measures - Invention and Innovation - Product Evaluation Technology - Electronic Technology - Technical Analysis - Measurement Engineering - Structures, Materials, and Life Safety — Building Environment * Technical Evaluation and Application * - Fire Technology.

THE INSTITUTE FOR COMPUTER SCIENCES AND TECHNOLOGY conducts research and provides technical services designed to aid Government agencies in improving cost effectiveness in the conduct of their programs through the selection, acquisition, and effective utilization of automatic data processing equipment; and serves as the principal focus within the executive branch for the development of Federal standards for automatic data processing equipment, techniques, and computer languages. The Institute consists of the following divisions:

Computer Services - Systems and Software - Computer Systems Engineering - Information Technology.

THE OFFICE FOR INFORMATION PROGRAMS promotes optimum dissemination and accessibility of scientific information generated within NBS and other agencies of the Federal Government; promotes the development of the National Standard Reference Data System and a system of information analysis centers dealing with the broader aspects of the National Measurement System; provides appropriate services to ensure that the NBS staff has optimum accessibility to the scientific information of the world. The Office consists of the following organizational units:

Office of Standard Reference Data - Office of Information Activities - Office of Technical Publications - Library - Office of International Relations.

\footnotetext{
${ }_{1}^{1}$ Headquarters and Laboratories at Gaithersburg, Maryland, unless otherwise noted; mailing address Washington, D.C. 20234.

2 Part of the Center for Radiation Research.

${ }^{3}$ Located at Boulder, Colorado 80302.

- Part of the Center for Building Technology.
} 


\section{Engineering and Construction Manual for an Instrument to Make Burn Hazard Measurements in Consumer Products}

Louis A. Marzetta

Measurement Engineering Division

Institute for Applied Technology

National Bureau of Standards

Washington, D.C. 20234

Prepared for

Consumer Product Safety Commission

Washington, D.C. 20016

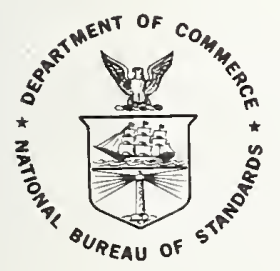

U.S. DEPARTMENT OF COMMERCE, Frederick B. Dent, Secretary

NATIONAL BUREAU OF STANDARDS, Richard W. Roberts, Director

Issued February 1974 


\title{
National Bureau of Standards Technical Note 816
}

\author{
Nat. Bur. Stand. (U.S.), Tech. Note 816, 48 pages (Feb. 1974)
}

CODEN: NBTNAE

\section{U.S. GOVERNMENT PRINTING OFFICE}

WASHINGTON: 1974

For sale by the Superintendent of Documents, U.S. Government Printing Office, Washington, D.C. 20402 (Order by SD Catalog No. C13.46:816). Price 85 cents. 
Abstract

1. Introduction . . . . . . . . . . . . . . . . . . . . . . 1

2. Design and Construction Details of the Probe . . . . . . . . . . . . . 1

2.1 Fabrication of the Probe with Ribbon-Type Thermocouple Element . 2

2.2 Fabrication of the Probe with a Finewire Thermocouple Element . 5

3. Circuit Description . . . . . . . . . . . . . . . . . . . . . 6

4. Placing the Instrument Into Operation . . . . . . . . . . . . . . 8

5. Testing Methods . . . . . . . . . . . . . . . . . . . . . . . 9

5.1 Test with Glass Reference Surface . . . . . . . . . . . . . . . 10

5.2 Fffect of Thermocouple Depth Variation . . . . . . . . . . . . . 11

5.3 Test with Plastic Coating on Metal Surface ............ . 12

5.4 Additional Comments on One Second leasurements . . . . . . . . .

5.5 Summary of Comments on the Topic of Contact mime and its

6. Influence of Variation in Thermal Inertia . . . . . . . . . . . . . . 14

6.1 Influence of Variation in Controlled Probe Temperature . . . . . 16

7. Summary of Errors . . . . . . . . . . . . . . . . . . . . . . 14

8. Additional Comments and Conclusions . . . . . . . . . . . . . . 15

APPENDIX A and B . . . . . . . . . . . . . . . . . . . . . . . . . . 16

References . . . . . . . . . . . . . . . . . . . . . . . . . 17

Table 1 List of Components and Materials . . . . . . . . . . . . . . 18

Table 2 Values of $\operatorname{erf}(y)$. . . . . . . . . . . . . . . . . . . . . . 21

List of figures . . . . . . . . . . . . . . . . . . . . . . 22 

Engineering and Construction Manual For an Instrument to Make Burn Hazard Measurements in Consumer Products

Louis A. Marzetta

Surface temperature measurement alone is insufficient to establish the hazard of human contact with a hot or cold object. A metal surface is more likely to cause thermal injury than a plastic surface at the same temperature. An instrument equipped with a measuring probe has been developed for indicating the tissue temperature that would be experienced if human contact were made with the hot surface in question. The correct value of interface contact temperature can be read for a selected contact time without knowing the composition or temperature of the heated material under test.

A detailed set of instructions and drawings for assisting in the construction of the device is included in the manual. Several test procedures are described for use in checking the performance of the measuring probe and instrument.

Key words: Consumer products; contact temperature; thermesthesiometer; thermometry.

\section{Introduction}

When assessing the burn hazards of solid surfaces it is a fact that a metal surface is more likely to cause thermal injury than a plastic surface at the same temperature [1]1. An instrument has been developed for measuring this effective burn hazard. The device is able to duplicate the tissue temperature that would be experienced if human contact were made to a hot surface regardless of its composition. The measured contact temperature can be translated to a qualitative evaluation of the hazard for the heated surface in question.

A principle from heat flow theory was selected as the basis for the instrument design. It can be predicted analytically that a steady-state interface temperature exists when two masses at different but constant temperatures are brought into contact. Laboratory tests confirmed the possibility of measuring this interface temperature. Since the purpose of the instrument system is to make a realistic contact measurement, the measuring probe was designed to simulate human tissue. By selecting a material for the instrument probe with thermal properties close to that of a human finger and temperature regulating the probe to the value for human tissue, the instrument reading accurately duplicates the temperature of an actual finger contact. A short analysis of the system development is currently being prepared for publication [2] The instrument is called a thermesthesiometer--a device for measuring the human sensibility to heat.

\section{Design and Construction Details of the Probe}

The construction of the probe is shown in a simplified schematic cross section in Fig. 1. A heater wire is wound around the inner core tube and a resistance thermometer transducer in physical form similar to a strain gage element is positioned along the central axis of the core tube. These two components form the basis of the temperaturecontrolling circuit that maintains the probe assembly at a finger-tissue temperature of $33^{\circ} \mathrm{C}$. The interface temperature-measuring thermocouple element is positioned about $0.01 \mathrm{~cm}$ beneath the outer surface of the probe face, while its electrical companion junction is located about $1.5 \mathrm{~cm}$ back in the temperature-controlled core region. All the components are encapsulated in the silicone-rubber compound. The probe is mounted in a holder for a comfortable hand clasp and is provided with a wiring cable and connector.

1 Figures in brackets indicate the literature references on page 17. 


\subsection{Fabrication of the Probe with a Ribbon-Type Thermocouple Element}

The assembly process of the internal probe elements begins by mounting of the front thermocouple; this step is followed by winding the temperature controlling heater coil; next, the $100 \mathrm{ohm}$ resistance thermometer is positioned along the central axis and the element lead wires are soldered to a terminal block that has been mounted in place: finally, the probe structure is encapsulated in its holder tube with the special silicone-rubber medium, and the external cable and probe handle assembly are installed.

Figs. 2 through 7 are a series of drawings for fabricating the mechanical components that make up the probe assembly, and in most part the drawings are selfexplanatory. To assist in visualizing the assembly process the sketch in Fig. 8 can be referred to as each step is undertaken.

The assembled thermocouple ribbon element is not at present commercially available from stock. It is necessary to obtain the two ribbon materials of Chromel and Alumel, about $0.1 \mathrm{~cm}(0.040$ inches) wide by approximately $0.0076 \mathrm{~cm}(0.003$ inches) thick, (see list of components and material). A thermocouple element is made from $2.5 \mathrm{~cm}$ (oneinch) strips of the two materials electrically spot welded with a junction overlap of about $0.025 \mathrm{~cm}(0.010$ inch).

STEP 1. Trim the thermocouple element to an overall length of $4.8 \mathrm{~cm}(1-7 / 8$ inch), $2.4 \mathrm{~cm}(15 / 16$ inch) each side of the welded junction). Prepare a pair of 7.6 $\mathrm{cm}$ (3-inch) lengths of plastic insulated (red and blue) \#30 tinned copper wire with ends bared for about $0.6 \mathrm{~cm}$ ( $1 / 4$ inch); insulated wire used for wirewrap applications is suitable. Wrap the bare end of the red insulated wire around the last $0.3 \mathrm{~cm}$ ( $1 / 8$ inch) end of the Alumel ribbon (the one that has magnetic attraction), solder the connection using a stainless steel flux. Attach the blue insulated wire and the Chromel ribbon in the same manner. Coat the soldered connections with ordinary liquid epoxy cement and allow to dry.

2. Carefully bend the ribbon element around two sides of a $1.3 \mathrm{~cm}$ ( $1 / 2$ inch) square wooden dowel with $0.15 \mathrm{~cm}$ (1/16 inch) radius edges to form a hairpin loop with a somewhat flattened top and slip the loop inside the probe core tube Fig. 2, and position it as shown in the assembly sketch of Fig. 8. Center the loop between the mounting holes in the lip of the core tube. Fine wire such as the \#30 used in step 1 can be twisted through the holes in order to hold the thermocouple loop in position; the loop should extend about 0.024 $\mathrm{cm}(3 / 32$ inch) beyond the core tube end. At this point it is important to insure that the thermocouple junction is precisely located uppermost at the loop tip and that the ribbon surface is correctly plane-oriented. For this step as well as others it is strongly suggested that an illuminated optical magnifier or stereo microscope of 5 to 20 power be available for adjustment and checking during the assembly process. Cement the element in place with liquid epoxy; do not coat the junction area with cement. The twisted wires holding the thermocouple can be clipped short and left in place.

3. Starting from the lower hole in the probe core body, the heater winding coil is wound upward towards the upper hole. The winding starts with a protruding length from the lower hole of about $3.8 \mathrm{~cm}(1-1 / 2$ inches) beyond the bottom end of the tube, and it should terminate at the upper hole with about the same length. The winding will consist of about 14 turns for a $74 \mathrm{~cm}$ (29inch) piece of the \#36 enamel insulated nichrome wire. Sharpened toothpicks may be used to hold the winding in place at the holes while liquid epoxy cement is applied to the winding and during curing.

4. Trim the sides of the DN-100 resistance thermometer element slightly to achieve a sliding fit inside the probe core tube. Slide the element in place in a right angle plane to the mounted thermocouple ribbon. This will place the element along the center of the tube with one of its edges alongside the heater winding holes. The top of the resistance element is set flush with the front face of the probe core tube: cement the element in place. Slip a $0.8 \mathrm{~cm}(5 / 16$ inch) length of teflon spaghetti over each lead, positioned near the element. 
5. Bend the copper wire junctions at the ribbon thermocouple inward at an angle of about 45 degrees as shown in Fig. 8. These connections form the reference junction which is to be embedded in the temperature-controlled RTV material.

Extra care is required in encapsulating the probe assembly to insure that the measuring thermocouple junction is precisely located at the depth equivalent to the dermal layer in human skin [3]. This is necessary if the probe is to accurately simulate the contact temperature response of a human finger. A casting assembly fixture with a built-in micrometer is used for this purpose. Fig. 6 is a construction drawing of the device and Fig. 7 is an assembly diagram showing the probe components in relation to the casting fixture.

6. At this stage all three of the electrical elements have been mounted in placr with their six wire leads protruding from the back end. These leads are to be attached to a terminal block in the next step. A suitable terminal junction block for the probe can be made by modifying a commercial component, a 14-pin integrated circuit socket ordinarily used with a printed-circuit board, such as Cinch - part no. 14-DIP-1. A pair of terminals is sawed away from each end of the socket leaving 10 terminals. The four corners can be rounded with a file, and the socket is fitted in place in the back cap section of the probe core tube. Before cementing the block in place the red and blue thermocouple lead wires are threaded through the center hole, the resistance thermometer leads are each brought through an end hole; the heater winding leads are threaded through the nearest opening along the side of the terminal block. The lead notation for soldering to the terminals is given in Fig. 9. A stainless steel flux is used with the heater winding after scraping away the insulation with fine sandpaper. Wherever possible a slack loop should be provided at each lead.

7. Turn the micrometer adjustment disc-screw in the casting fixture so that the movable brass end plate rests about $0.3 \mathrm{~cm}$ ( $1 / 8$ inch) below the ledge of the aluminum body; this distance is to allow sufficient clearance for the $0.24 \mathrm{~cm}$ (3/32 inch) protrusion of the thermocouple loop tip at the probe core tube.

8. Place the lucite probe body Fig. 4 (part C) in place in the casting fixture with the internal ledge in the upright position. Make a mark on the lucittube at its bottom exterior that coincides with a mark made on the aluminuin fixture body. Iock the lucite tube in position with the side thumb screw.

9. Slide the probe core tube assembly inside the lucite tube until it seats firmly in position. The assembly can be held in place with a small toolmaker's clamp. Make a positioning mark on the inner core tube that coincides with a mark made at the inside of the lucite tube. This set of marks and the set described in step 8 are for use in precisely repositioning the components.

10. Connect an ohmmeter between one of the thermocouple terminals and the locking screw on the side of the casting fixture.

11. Turn the micro meter adjustment inward at the point where the ohmeter just indicates that the thermocouple junction has contacted the micrometer plate. This represents zero equivalent skin depth. Back off the micrometer adjustment by the desired equivalent depth; the micrometer screw has a travel of $0.0635 \mathrm{~cm}(0.025$ inches) per revolution. A setting of between 0.0076 and $0.0125 \mathrm{~cm}(0.003$ and 0.005 inches) depth is suggested. Note the zero and final adjustment points on the micrometer adjustment disc-screw by means of appropriate markings. 
12. Revert to Step 7 and repeat the procedure several times to insure that the final value depth adjustment can be repeated to a precision of around 0.0025 $\mathrm{cm}(0.001$ inches). Coat the inner and outer surfaces of the thermocouple loop, including the junction area, with a coating of Eccosil Primer No. 33 , and let dry. The purpose of this coating is to insure the adhesion of the silicone rubber material to the thermocouple.

In the search for a suitable material to be used in encapsulating the probe assembly several factors were considered. The part of the probe that would be pressed against the various heated surfaces should have some resiliency; it would have to withstand high temperature exposure, as much as $200^{\circ} \mathrm{C}$. The material would need an initial flow property to allow a near perfect encapsulation of the intricate assembly. Finally, the thermal properties of the substance should combine to yield a thermal inertia close to that of human tissue in order to satisfy the "simulated" finger analysis. A silicone-rubber material seemed a likely choice. Several companies offer silicone products that have been doped with metal compounds in order to tailor their thermal characteristics. One such material is ECCOSIL 4952 ; it is a two part pourable RTV silicone-rubber compound with the required thermal inertia.

13. The encapsulating process begins with the preparation of the RTV material. The bulk portion of the material should be thoroughly mixed in its original container by means of a stirrer rod in a drill press as well as hand stirring with a heavy spoon. The substance has a thick consistency and a tendency to settle out heavily at the bottom of the container.

14. Weigh out, 100 grams of the stirred bulk material in a paper cup on a platform balance.

15. Add 0.5 grams of the liquid catalyst to the cup with the aid of a medicine dropper while the cup is on the balance.

16. Stir mixture vigorously with a spoon.

17. Place the cup in a vacuum chamber and evacuate until a head of bubbles break at the surface of the RTV material. Break the vacuum and stir the material again.

18. With the aid of a disposable funnel made from a square piece of paper having about a $0.6 \mathrm{~cm}$ ( $1 / 4$ inch) spout opening, fill the probe lucite body that has been mounted in place in the fixture described in step 8 to a level of about $0.6 \mathrm{~cm}(1 / 4$ inch) below the inner ledge of the lucite body.

19. Lower the inner probe assembly into the liquid material taking care to orient it according to step 9. Lower the assembly slowly and finally firmaly against the shoulder stop; hold in place with a small toolmaker's clamp.

20. Place the fixture in the vacuum chamber and bring vacuum down to the point where bubbles are breaking at the surface, but do not pump down further in order to avoid excessive RTV material rising into upper chamber of the probe core. Hold the vacuum for about 8 minutes, then gently release the vacuum. Allow the assembly to cure in the chamber in ambient air for a period of about 24 hours.

2

Certain commercial components and materials are identified in this report in order to specify the experimental procedure adequately. In no case does such identification imply recommendation or endorsement by the National Bureau of Standards, nor does it imply that the material or component identified is necessarily the best available for the purpose. 
21. After the curing period the encapsulated probe can be removed from the fixture and made ready for assembly to the handle and cable. A six-conductor cable is cut to a rough length of $127 \mathrm{~cm}$ (50 inches). One end of the cable is threaded through the hole in the probe handle. Connections to the terminal block in the probe can be made according to details in Fig. 9. A cable clamp is secured above the terminal block connections for the purpose of relieving any strain on the connections after the cable has been pulled in place in the handle. The remaining end of the cable is attached to a male panel connector as shown in Fig. 9. During this assembly a $0.9 \mathrm{~cm}$ ( $3 / 8$ inch) length of teflon spaghetti should be slipped over each soldered pin connection. Finally, check the entire cable assembly with an ohmmeter for continuity of correct end-to-end connection, a check of freedom from crossleakage, and the correct ohmic readings for each of the probe elements according to values in Fig. 9. The probe handle is held in place as a result of its machined snug fit in the remaining probe assembly; if looseness exists it can be remedied with a coating of cement. Remove any raised edge at the probes face resulting from the encapsulation process.

\subsection{Fabrication of the Probe with a} Fine Wire Type Thermocouple Element

To date there have been nine different models of probe constructed. The details presented here represent the latest version of a suggested design. Evaluation tests are being continued with the device; its experimental nature implies that future modifications in design can be expected. It is also likely that variations of probe geometry will be considered in order to adapt the instrument to new and varied forms of thermal measurement applications.

The previous description of probe construction was centered around the use of a fabricated ribbon-type thermocouple. If there is difficulty in obtaining chromel and alumel material in ribbon form or if there are problems in making the welded junction, it is possible to use the commonly available round-wire thermocouples. However, it is the author's opinion that the ribbon-type thermocouple may be a better configuration for the probe. Bare chromel-alumel thermocouples, $0.0076 \mathrm{~cm}$ ( $3 \mathrm{mil}$ ) diameter wire, can be readily obtained with a round ball, welded tip. A probe can be constructed using this type of thermocouple but it will be necessary to modify the first five step instructions, as follows:

Step 1 (modified) The ribbon type thermocouple is physically replaced by a strip of vinyl material about $4.1 \mathrm{~cm}$ ( $1-5 / 8$ inch) long, approximately $0.0076 \mathrm{~cm}(0.003$ inches) thick. Bend the vinyl strip into a flattened hairpin-like loop as described in the previous step 2, and slip the loop inside the probe core tube while centering the loop between the mounting holes in the lip of the core tube. As described for the ribbon thermocouple, the loop can be held in place with fine wire; the loop should extend beyond the core tube end by about $0.24 \mathrm{~cm}(3 / 32$ inch). Cement the strip in place with the two-part liquid epoxy adhesive.

2 (modified) Locate and cement the thermocouple bead junction on the outside centerline of the strip, and very precisely set the bead in its upright position at the topmost point of the strip arc. An optical magnifier or stereo microscope is necessary during this procedure. The base leads are brought down the outside surface of the plastic strip, with a genereous separation, to the rim of the core tube end as shown in Fig. 10, and are cemented down the inside of the core tube.

3 (unchanged) Starting from the lower hole in the probe core body, the heater winding coil is wound upward towards the upper hole. The winding starts with 
a protruding length from the lower hole of about $3.8 \mathrm{~cm}$ (1-1/2 inches) beyond the bottom end of the tube, and it should terminate at the upper hole with about the same length. The winding will consist of about 14 turns for a 74 cm (29 inch) piece of the \#36 insulated nichrome wire. Sharpened toothpicks may be used to hold the winding in place at the holes while liquid epoxy cement is applied to the winding and is subsequently drying.

(modified) Trim the sides of the resistance thermometer element with scissors to achieve a sliding fit inside the probe core tube. Remove the element and make two pairs of mounting holes in the bottom area of the element for use as junction points for thermocouple ends and the copper lead wires as shown in Fig. 10. Loop the copper lead wires through their mounting holes at the resistance element, and slide the element into the probe core tube, part-way along the center of the tube, with one of $i$ ts edges along the inside of the heater winding holes. At this point the bare thermocouple leads are trimmed to a suitable length and are attached to the copper wire junctions. The alumel (magnetic) wire is soldered to the red insulated lead using the stainless steel flux and the chromel wire to the blue lead. Slip the resistance element in place in the tube to where it is flush with the end face of the core tube and is at right angles to the thermocouple strip loop. Carefully check to see that the bare thermocouple wires are properly routed down the inside of the tube before looping over to the end of the resistance element; the wires must not touch each other. Cement the element in place as well as any loose thermocouple wires. Coat the thermocouple copper junctions with cement, and slip a $0.8 \mathrm{~cm}$ (5/16 inch) length of spaghetti over each of the resistance element leads.

5 (deléte).

6 through 21 Same as previous description.

\section{Circuit Description}

The circuit shown in Fig. 11 is the complete electronic diagram of the instrument. The circuit can be broken down into two major sections an analog section is used for amplification and temperature control, and the digital circuitry is concerned with timing and output indication. Integrated circuit components are used for both the analog and digital sections. The digital panel meter is a standard, compact 3-1/2 digit package with a full-scale sensitivity of $199.9 \mathrm{mV}$. A standard $5 \mathrm{~V}$, lA supply module powers the digital circuitry and the panel meter, while a $5 \mathrm{~V}$ to $\pm 15 \mathrm{~V}$ converter module is used with the operational amplifier circuitry.

A $100-0 h m$ resistance thermometer located within the probe is used in a bridge circuit at the input of amplifier Al for the temperature regulation of the probe at $33^{\circ}$ $C$. Power amplifier $Q 1$ supplies the probe heater current. In the event the probe absorbs too much heat from prolonged contact with a hot surface, the temperature controller will indicate this condition by an indicator lamp actuated by transistor Q2 and the imbalance signal from $\mathrm{Al}$. It is necessary to equip the instrument with an aluminum plate at room temperature in order to avoid excess heating of the probe. After each reading the probe is brought into contact with the heat sink for a few seconds to remove the excess heat. Amplifier A2 is highly stable and amplifies the chromel-alumel thermocouple output. Chromel-alumel material was chosen for its high linearity of output voltage versus temperature and for its rugged physical properties.

The function of the digital timing circuitry is to allow the selection of a precise contact measuring time with the following timing sequence. Within a few milliseconds after firm contact between the probe face and hot surface under 
measurement, the digital panel meter logic circuitry delivers to the pulse generator circuit Ul, an initiating positive voltage step corresponding to the $40^{\circ} \mathrm{C}$ crossing of the meter reading. The actual timing takes place at U2 upon receiving a pulse from Ul. A front-panel switch allows the selection of contact reading times of $1,2,4$, or 8 seconds. At the end of the timing period, JK flip-flop stage U3 supplies a gate pulse to the digital panel meter via $\mathbf{3}$, which causes the last temperature reading at the meter to be "frozen" for ease of reading. Panel indicators alert the operator to the functioning of the timing sequence, and a push-button is used to reset the meter before each new reading.

There are no scale-factor calibration controls in the instrument. Initially the electronic circuit is adjusted for a controlled temperature of $33^{\circ} \mathrm{C}$ at the probe by means of a bias adjustment at the input of stage $\mathrm{Al}$, using an independent thermometer for measuring the probe temperature. After the controlled temperature of the probe has stabilized, a second control located at the input of stage A2 is adjusted for a reading of 33 degrees at the digital panel meter.

The majority of the electronic components are located on a double sided printed circuit board; the components include the analog and digital active integrated circuits and their associated resistors and capacitors. The +5 volt to \pm 15 volt dc to dc converter module is located on the board, and a male connector plug mounted on the card for the external leads. The board also includes the adjusting pots for the probe temperature control and the $33^{\circ} \mathrm{C}$ digital panel reading.

Fig. 12 and Fig. 13 are layouts of the two sides of the printed circuit board. A list of component values is given in Table 1 . All components including the dc to dc converter, are mounted on the side of the board shown in Fig. 14.

The printed circuit board is fabricated by the standard photo-etched process using copper-clad fibre-glass board material. The resultant printed circuit was plated for ease in component soldering. Since the project was an engineering development effort, the active components were made to plug into socket terminals mounted on the board for ease of component exchange; however, new users may wish to solder the active components. directly in place. In the case of the IC operational amplifiers A1, and A2, spring sockets were soldered into the board, AMP Corp. part no. 50462-8, using a no. 55 drill for the board holes. Walden/Molex IC Soldercon Terminals no. 05-30-001 were used on the board for the digital logic modules U1, U2, and U3; a no. 70 drill was used for the board holes in this case. The board connector was made up from AMP post pins, part no. 85931-6 using a no. 63 drill for the board holes, a push fit for the pin shank tab. Care should be taken when soldering these pins into the board to insure that the solder does not wick up the sides of the pin, othervise poor physical mating with the cable connector will result. The cable connector is AMP part no. AMPMODU 1-86256-7 with AMPODU contacts no. 86015-2 attached to cable leads by means of the appropriate AMP crimping tool. The remaining components in the board are soldered in place in holes made with a no. 60 drill. All drilling is done from back side of the board, Fig. 13.

It is very important to be aware of the numerous feed-through connections that have to be made between the board surfaces. In most cases the feed-through connection is made by the leads of a resistor or capacitor. Note that there are printed connections on both sides of the board at some of the IC terminals; take care in soldering not to allow any molten solder to flow into the openings of the IC socket receptacles. 
It is assumed that the instrument has been properly wired according to the wiring diagram in Fig. 11. Correct value fuses have to be inserted in their locations; one fuse in the primary power line of the master five volt power supply and the other one in the five volt line that feeds the digital panel meter. Two operational amplifier IC modules and three digital IC modules have to be plugged into their locations at the printed-circuit board; take care to orient the digital IC modules according to the information shown in Fig. 14. The following are suggested steps for setting up the initial adjustments to the system.

STEP 1. Before turning on power set the two trimming potentiometers located at the bottom side of the printed-circuit board to their maximum ccw position, approximately twenty complete turns.

2. Connect the probe to main instrument by means of the panel connector; connect the power cable to the rear of the instrument; turn the power switch to ON. position; push reset button panel.

3. Adjust the trimming resistor pot. Rl7 in a cw direction until the panel meter reads $33^{\circ} .0$. This control does not affect the temperature control of the probe; rather it is the system temperature datum level. However, the selected value of $33.0^{\circ} \mathrm{C}$ corresponds to the controlled probe temperature which in turn relates to the specified human tissue temperature of $33.0^{\circ} \mathrm{C}$. Allow the device to warm up for 30 minutes and re-adjust R17 for a 33.0 reading if necessary.

4. Adjust trimming resistor pot. $R 5$ in a $\mathrm{CW}$ direction until the overheat LED panel indicator extinguishes. The control sets the controlled temperature of the probe. What is wanted is a control temperature of $33.0^{\circ} \mathrm{C}$ at the internal section of the probe. Since this measurement is difficult, an external temperature check has been found to be effective. The working surface of the probe is monitored with a fine-wire thermocouple used in conjunction with a temperature-indicating instrument. Adjustment $\mathrm{R} 5$ is brought up $\mathrm{CW}$ in $1 / 4-$ turn increments with about a five-minute wait between settings until the probe face temperature is measured to be between 31 and $32^{\circ} \mathrm{C}$. These values correspond to the values obtained experimentally on the surface of human skin. The panel meter of the instrument will show a reading of about 32 degrees if the probe is left resting and untouched at its face for a room temperature near $25^{\circ} \mathrm{C}$.

An additional simple check on the operation of the instrument can be made at this time. If the probe face is brought into contact with a slab of brass or aluminum that has been resting at room temperature, the instrument will show a contact temperature reading that is one or two degrees above the room temperature for a contact time of about 10 seconds. If the room temperature material that is contacted happens to be non-metallic such as wood or plastic the instrument reading will be significantly higher, perhaps only a degree or so below the 32 degree quiescent level. "This corroborates the sensation of coldness when human contact is made with metal objects at environmental temperatures.

The following suggestions are based on experience to date. The manner of holding the measuring probe described here is suitable for most working areas; however, there may be situations with surfaces oriented in ways that require a different grasp of the probe. For normal measurements the lucite probe body is held with the thumb on the front side facing the user and the middle and forefinger on the opposite side. The other two fingers are tucked into the palm away from contact with the hot surface. 
The greatest expertise to be mastered is the initial contacting of the heated surface with the probe face. This author found that the best results were obtained by using a wrist motion with some snap action. The objective is to bring the probe face up parallel to the surface in a quick movement, resulting in a firm, square and positive contact. This dexterity is necessary to insure precision measurements, especially at the one-second contact time. After a short period of experience, the operator can expect a repeatability of measured temperature to within two degrees for more than $90 \%$ of the trials. In the case of four-and eight- second contact time measurements, the application of the probe to the working surface is not as critical as with the shorter time tests.

As indicated elsewhere in this report the degree of contact pressure that is applied does not noticeably affect the readings; a 4 to 8 newtons (one- or two- pound force) is suggested. After noting the panel reading the Reset button can be pressed to cancel the reading in preparation for the next test. The usual meter reading before each measurement with the probe not in contact with any surface will be between 30 and 34 degrees. The operator should remember to apply the probe to the room-temperature aluminum plate between readings.

Experience obtained in the construction of several models of the instrument shows that the accuracy of the $1,2,4$, and 8 second timing is assured if the stated values and tolerances of components: R29, R30, R31, R32 and C3 are adhered to. However the timing should be checked. This can be done by bringing the probe in contact with a heated metal surface of about 60 to $70^{\circ} \mathrm{C}$. Each of the selected contact times can be checked by measuring the interval between the activation of the Time and Read panel lights with the aid of a stop watch. The agreement at one second contact time should be within 0.15 seconds and within 108 of the other selected values.

Temperature Iimitation of Probe: The maximum temperature reading of the instrument is $199.9^{\circ} \mathrm{C}\left(392^{\circ} \mathrm{F}\right)$. While the silicone rubber probe material is commercially rated to withstand an exposure of about $255^{\circ} \mathrm{C}$ (490 ${ }^{\circ} \mathrm{F}$ ), it is suggested that the probe not be subjected to contact times greater than 4 seconds for temperatures between 125 and $200^{\circ} \mathrm{C}$. This is to insure that the thermal properties of the material are not affected, otherwise the accuracy of the instrument may be degraded There is some evidence that a repeated exposure of the silicone rubber material to temperatures above $100^{\circ} \mathrm{C}$ causes a gradual hardening of the substance. At no time should the probe be allowed to be subjected to a temperature above $275{ }^{\circ} \mathrm{C}\left(527^{\circ} \mathrm{F}\right.$ ), even for a brief instant; this will permanently damage the probe.

\section{Testing Methods}

In the previous discussion in section 4 the two circuit adjustments were concerned with the initial settings for the controlled probe temperature and for its quiescent reading. There are no scale factor or calibration controls. The measuring system was designed on the principle of a calculable transducer whose transfer function was described previously. The signal amplification is fixed by means of precision value resistors $\mathrm{R} 22$ and $\mathrm{R} 19$, at stage A2 in Fig. 11, so that a correct normalized value of contact temperature will be read by the digital panel meter for a probe constructed from a chromel-alumel sensing thermocouple. The amplification has been normalized at 24.3 to correspond with the chromel-alumel thermal emf of $41.2 / \mathrm{N}^{\circ} \mathrm{C}$, between 33 and $63^{\circ}$ C. This results in a transfer function of $1 \mathrm{mV} /{ }^{\circ} \mathrm{C}$ at the digital panel meter. The validity of the readings from an instrument designed along the stated principles can be substantiated by comparing the experimental test values of temperature with those values obtained by calculations from theory. This test procedure will be discussed next. 
This test ascertains if the instrument reading is a true measure of the contact temperature as predicted from heat flow theory. A glass material is a suitable working surface and it can be used as a heated reference standard. In addition to its stable qualities, glass has a thermal inertia that is desirably located between high thermal conductivity metals and low conductivity plastics. A suggested standard reference glass is Corning type 7940 fused-silica. It is a stock item available in a number of physical sizes; a convenient one is about $5 \mathrm{~cm}$ (two inch) disc with a thickness of approximately $1.25 \mathrm{~cm}$ (one-half inch). The optical grade with a no. 2 finish is suitable for the application. A substitute material is a flat piece of window glass about one $\mathrm{cm}$ thick. With a knowledge of the values of the various thermal parameters it is possible to calculate from heat flow theory the contact temperature at a given surface temperature of the heated glass material. This temperature can be compared with the instrument reading obtained by contact of the instrument probe and the heated glass surface.

The procedure is to heat the glass material on the surface of a hot plate. (A controlled temperature water-bath technique can be used.) An adjustable transformer is used to set the input electrical power at various levels. The temperature of the reference glass surface is measured with a fine wire thermocouple $(0.0075 \mathrm{~cm}$ or less) in conjunction with a digital indicating thermometer having one-tenth degree resolution. The thermocouple bead tip can be pressed down on the glass surface by the use of a very low density material such as a small piece of silicone foam rubber; in the case of surface temperatures below $85^{\circ} \mathrm{C}$ a small piece of packing material-styrofoam plastic-may be used. A commercial surface-thermocouple, sensing probe may be used in place of the fine wire element for ease of handling; one such device is the Model $68004-\mathrm{K}$ surface probe made by the Omega Engineering Co. However its greater mass can be expected to contribute a greater offset reading error than a fine wire thermocouple. For a surface temperature of $80^{\circ} \mathrm{C}$ the fine wire element may read one or two degrees low whereas the commercial sensing probe may have an offset of four or five degrees at this temperature. The measurement of surface temperature $T_{h}$, is probably the principal source of error in the testing procedure.

The object of the experiment is to vary the temperature of the glass surface in a step-wise fashion over a range from about 50 to $100^{\circ} \mathrm{C}$. At each step the stable surface temperature $T_{h}$ is recorded and the contact temperature $T_{c}$ is measured by the probe and instrument. The instrument contact time is set to four seconds, which means that the reading is essentially a steady state value of $T_{c}$. Figure 15 is a plot of the instrument values of $\mathrm{T}_{c}$ at each measured value of $\mathrm{T}_{\mathrm{h}}$ in relation to a locus line representing the values of $T_{c}$ as calculated from heat flow theory and described in Appendix A. All measured points are included in the figure for this representative test run. If an instrument and probe have been constructed according to the stated principles, the comparison results for this particular test should show an agreement between the measured $T_{c}$ and the calculated value to within plus or minus three degrees over the indicated range.

The expectancy of measurements within \pm three degrees of the correct value of $T_{c}$ is a statement of accuracy. The observed operational precision shows a repeatability of measurement where more than $90 \%$ of the readings can be expected to have a total error of \pm 2.0 degrees or less. This is a test of repeating the $T_{c}$ measurement with the probe and insuring that the glass $\mathrm{T}_{\mathrm{h}}$ temperature remains invariant from each testing point to the next one. This is also a good test to demonstrate the fact that the applied pressure between the probe face and the heated surface is not critical; the force applied can be varied over a large range but a force of 4 to 8 newtons (one or two pounds ( has been found to be both satisfactory and comfortable. This insensitivity to contact pressure and to a deliberate introduction of a water or oil film to the probe face (though not recommended) indicates the contact resistance interface between the probe and the heated mass can be neglected. 
The previous test was a series of temperature readings of $T$ for a fixed contact time of four seconds. This means that in the region of the measuring thermocouple at the probe face there has been sufficient time to reach temperature equilibrium, and there is practically no temperature difference between the probe surface and a plane at the thermocouple depth. While the previous test was a valid check on the instrument's ability to measure a quasi steady-state contact temperature, the test did not yield sufficient information to establish a complete correspondence to human contact. If the thermocouple element had not been encapsulated at the correct depth corresponding to the dermal layer in human skin, the previous test will not reveal the defect. The following test procedure offers a means of determining the equivalent skin depth location of the encapsulated thermocouple element at the probe face; in addition the test data presents information to check the short-contact-time (one second) response of the probe. Also the profile of the plotted contact temperature as a function of time when applied to a heated surface of unknown composition can offer clues as to its thermal behavior.

Using expressions derived from heat flow theory and presented in Appendix B, a series of curves was calculated using four different values of depth measured from the probe face to the thermocouple junction corresponding to different depths of the dermal layer in human skin tissue. The results are shown in Fig. 16. The abscissa is the contact time and the ordinate values are the temperature at the various depths.

The analysis procedure is the plotting of experimental probe data on the figure and comparing its profile with the existing curves. The broken line function in Fig. 16 is plotted from values measured with the probe. Contact temperature measurements, Tc were made with the heated glass reference held precisely at a constant temperature $T h$. before each of the $1,2,4$, and 8 second contact readings. The exact value selected for the heated surface is not important (between 80 and $90^{\circ} \mathrm{C}$ is suggested); the same temperature must be maintained for each of the time tests. The four values of contact temperature are plotted on the figure; for ease of comparison an arbitrary fixed value of abscissa shift was added to each temperature in order to place the curve conveniently between a pair of the existing functions in the figure. of concern here is the slope-profile of the plotted probe data. In the example in the figure the slope of the test curve appears to be almost equivalent to the no. 2 function, perhaps a bit less. This means that the measuring thermocouple junction was encapsulated below the probe face at between one and two equivalent "epidermal skin" depths. This seems to be typical for probes built to date. If the plotted test curve had shown a slope closer to the no. 4 function, it could be suspected that the probe sensing element was set too deep and would not be acceptable. For such a probe the contact temperature values for 8 seconds contact time would be reasonable but the one-second readings would be much too low as indicated in the figure. Note that the ordinate values in this figure have been physically expanded in order to accentuate the slope differences.

If a probe has been found to have a thermocouple junction set too deep it may be possible to remedy the situation. Some of the RTV material can be carefully removed from the probe face by gently rubbing it against a fine grade of silicon carbide paper, (about 600 grade); the face should be checked with a straight edge. (It is important in these tests that the probe face be flat and be free from a raised edge produced during encapsulation of section 2.1). The described procedure can be used to monitor the degree of material removal by observing the improvement in the slope at the one and two second region, but in no instance should the material removal expose the thermocouple element.

The argument presented here is that the sensing element depth was responsible for the slope-contour of the probe response curve. While the sensing depth is the principal factor, the probe response is also influenced by the small but unavoidable thermal time constant of the thermocouple element. Probably this added factor accounts for the typical probe having a response slope somewhat greater than expected even 
though the thermocouple junction may have been set precisely to a single "skin" depth at encapsulation. The small discrepancies in sensing depth can be neglected since the error involved is within the assigned accuracy of the instrument. Also, there is debate concerning the correct skin depth since the dermal layer varies between individuals, as well as from one part of the body to another.

\subsection{Test With Plastic Coating on Metal Surface}

The previous tests show that a probe tested in the manner described and found to have its sensing element correctly set should not imply that all future measurement data could not show an anomalous behaviour as indicated by an extra-large slope in the time-response curve. The test was conducted on the fused-silica reference surface, which is a nearly ideal semi-infinite-length thermal mass. There will be heated surfaces encountered in practice that are far from ideal whose contact temperature as a function of contact time is impracticable to predict from theory. Indeed, it is the contact ime flexibility of the instrument that allows a correct reading to be made with these thermally-complex cases. Fig. 17 shows the results of a test on a heated surface altered by a plastic coating. A thick piece of brass was maintained at a constant $T_{\mathrm{b}}$ temperature, and a series of contact-temperature readings at the contact times were hade and plotted in curve A. A portion of the brass surface was covered with a piece of $0.013 \mathrm{~cm}(0.005 \mathrm{inch})$ teflon tape, and the tests were repeated on this surface. The second test data is plotted in curve $B$, and it is obvious that there is a much larger slope to curve $B$, especially in the 1 and 2 second contact-time area. Though the plastic film is thin, its lower thermal conductivity has influenced the transport of heat. This example has potential practical significance; it suggests that the makers of consumer products can use the instrument as a design tool to meet safety specifications. The simple expedient of covering a hot surface with a thin coating of plastic can significantly reduce the contact temperature at all contact times and especially so for short contact times. This latter point is important since the situation of brief contact with hot surfaces is very dangerous and is of increasing concern.

\subsection{Additional Comments on one Second Measurements}

The electronic details of the instrument and some features of the probe could be simplified by designing the measuring system for a fixed contact-measuring time of , say, four or eight seconds. By reducing the circuit complexity, the fixed longer measuring time would have reduced depth positioning tolerance of the thermocouple element in the probe to some degree since the thermal gradient from probe face to sensing element becomes quite small at contact times above four seconds. With a single measurement with the longer contact, time it would be possible to predict the one-second contact time temperature by an extrapolation of the data using scale factors taken from curve 1 or 2 in Fig. 16. For the majority of applications the results are valid, but it is possible that a heated surface such as the one described in conjunction with Fig. 17. might be encountered. It is possible with non-ideal thermal masses to have anomalous readings with one second contact. There are significant operational advantages with the short measuring periods. A larger number of points at a surface can be covered than with a longer measuring time. Also the repeated measurements at the longer periods require a correspondingly long time interval between readings in order to remove the excess heat from the probe with the aid of the passive plate. The routine manner for using the instrument will be to make a series of quick measurements of a heated surface with the instrument set to a one-second contact time. Whenever a suspicious temperature has been read the procedure will be to make a series of readings at the location at all the contact times. It may be desirable to make a simple graph plot of this data for the record and subsequent study. Accuracy of the data is likely to be better for a four-second measurement than at one second, the smaller contact time demanding a greater dexterity of the operator. 
The one-second contact measurement time has an additional relationship with the operation of the instrument. The ordinate values in the physiological curves of Fig. 18 are for steady-state surface contact temperatures rather than dermal temperatures; this conforms with the related data found in the literature. The temperature difference between surface and dermal skin regions is most noticeable at the short contact times. Because this difference is a function of contact time, the dermal temperature is not constant throughout the cor.sact period. Hence the indicated temperature is slightly higher than the physiologically effective value. Conversely the thermal response lag of the thermocouple element causes the instrument reading to be on the low side. The two errors taken individually are small, but since they have an opposing effect, the net error is almost negligible. Any error is undoubtedly submerged in the uncertainty of the physiological data with one second contact, since this data was extrapolated from tests on skin where the shortest direct observation time of tissue damage was for a five-second application of heat.

5.5 Summary of Comments on the Topic of Contact Time and its Relationship to the Physiological Data of Fig. 19.

Currently it is impossible to state how safety regulations will be worded with respect to limits of contact temperature and contact time. The interest in a onesecond contact stems from the commonly experienced momentary touch with a hot surface followed by the reflex action of fast withdrawal. It has been found that the pain sensation and reaction is established in about 0.4 to 1.0 seconds. The one-second contact time is also unique because the threshold-of-pain temperature coincides with the skin-damage temperature in this time area. This is in contrast to the wide temperature separation between initial pain and skin damage for the four-second contact region as shown in the physiological curves of Fig. 18. [4] The upper solid-time curve in Fig. 18 is the temperature at which epidermal destruction can be expected, as a function of contact time. The curve immediately below the one described is the threshold of epidermal injury that may be reversible. The lower dotted curve is the threshold of pain sensation.

A safe value of dermal contact temperature for a four second measurement is unconditionally safe for a one second contact. However, a safe measurement value at one second is not necessarily safe at four second contact. One reason for this statement stems from the physiological response curve which shows that the hazarious contact temperature is about 10 degrees higher at one second contact than it is at four seconds. In addition, due to the dermal-depth gradient function the measured value of contact temperature is lower at one second than at four seconds.

Clearly it would be easier to meet the safety standards for a one seccnd contact than for the four second time. Also, (see section 5.3), simply coating a hot surface with a thin plastic can result in a dramatic decrease of contact temperature, particularly for one second contact. This procedure could lead to a dangerous situation. For example, a steel surface can be covered with a plastic coating less than $0.015 \mathrm{~cm}(0.006 \mathrm{inch})$ thickness. For a surface temperature of $102^{\circ} \mathrm{C}$, the contact temperature on the plastic coated steel is 60 degrees for a one second contact - a value that could be rated safe. Yet the four second contact temperature on the same surface would be 73 degrees - a value that is well into the hazardous region. 


\section{Influence of Variation In Thermal Inertia}

An exact value for the thermal inertia of the RTV material in the probe is not required. Likewise, small variations in the controlled probe temperature $T_{p}$ will not significantly affect the measurement accuracy of the instrument. Expression (1) in Appendix A shows that these factors, in virtually all cases, have less than a one-toone effect on the value of $T_{c}$. For example an analys is of (1) was conducted allowing for an exaggerated variation in the ratio of $\lambda_{h} / \lambda_{p}$ and determining the resultant variation of $\mathrm{T}_{C}$ for several different heated materials. The results are shown in $F$ ig. 19 for a minus $50 \%$ uncertainty in the correct value of thermal inertia $\lambda_{p}$. The graph shows that a glass surface at $70^{\circ} \mathrm{C}$ would have its contact temperature read $6 \%$ high or 3.5 degrees $\left(T_{C}\right.$ of glass is about $50^{\circ} \mathrm{C}$ for the stated $\left.T_{h}\right)$. In the case of a heated metal surface at the same surface temperature the error would be about 1.5 degrees. Since the uncertainty in the thermal inertia of the probe material is likely to be less than 208, the net error may be neglected.

\subsection{Influence of Variation in Controlled Probe Temperature}

The effect of a variation in the controlled probe temperature on the $T_{c}$ reading can be explored. Fig. 20 shows the results of calculations of the error at $T_{c}$ for various heated materials using an exaggerated $27 \%$ in the controlled probe temperature. As in the preceding example, the error is quite small for metal surfaces and increases for materials with low thermal inertias.

Fig. 20 is based on values calculated from the heat flow formula of expression (1) in Appendix $\mathrm{A}$. In practice, a variation in the internal probe temperature $T_{p}$, would also affect the reference junction of the measuring thermocouple. The error \&ue to the variation in reference junction temperature is opposite in effect to the error shown in Fig. 20. Hence the net error in practice would be less than shown in many materials and it could be a negative percentage error for metals. It may be advisable to design a probe with an external reference junction for anticipated work in a high temperature environment - over $33^{\circ} \mathrm{C}$.

\subsection{Sumary of Errors}

The following is a summary of the possible instrument errors. Since the magnitudes of the first two errors listed are a function of the heated surface's thermal properties, the stated values are for the heated glass standard. The errors would be less for heated metal surfaces.

Error in $\mathrm{T}_{\mathrm{c}}$ due to a 208 deviation from assumed value of thermal inertia for the RTV material used in the probe.

Error in $\mathrm{T}_{c}$ due to a 158 variation in the controlled probe-face temperature $\mathrm{T}_{\mathrm{p}}$.

Error tolerance for chromel-alumel thermocouple wire at $60^{\circ} \mathrm{C} .1 .28$

Linearity error for chromel-alumel thermocouple plus

electronic amplification uncertainty. 
For uncorrelated errors the rms

Net error $=\sqrt{(3.2)^{2}+(2.5)^{2}+(1.2)^{2}+(0.25)^{2}}=3.65 \%$

For the standard reference glass surface at $90^{\circ} \mathrm{C}$ and a contact temperature of $60^{\circ} \mathrm{C}$, the $T$ error is $\pm 2.2^{\circ} \mathrm{C}$. Over a period of six months involving many hundreds of measurements with eight different probes, the observed errors have been within the stated figure in most tests. This is the basis for rating the accuracy of the instrument, as noted in section 5.1 to be about $\pm 3^{\circ} \mathrm{C}$ over the operating region of interest - namely from 45 to $75^{\circ} \mathrm{C}$ for $\mathrm{T}_{\mathrm{C}} \cdot$

\section{Additional Comments and Conclusions}

Various other tests were conducted with heated reference materials ranging from high conductivity metals such as copper down to insulating plastics and natural wood. In almost all cases the comparison errors between measured and calculated values of $T_{C}$ were within 3 degrees. A similar degree of conformity was observed in comparisons between the instrument values and interface temperatures made with actual finger contact on a number of surfaces. A few brief observations were taken with heated nonsolid surfaces such as heated air and water. In all situations, regardless of the medium, if a particular environment caused a finger pain sensation for a 3 to 5 second exposure time, the probe-instrument for the same exposure would read between 45 and $50^{\circ}$ $\mathrm{C}$ as indicated on the human pain threshold line in Fig. 18.

This was especially evident in the case of blowing hot air at $65^{\circ} \mathrm{C}$ from a hair dryer and near still, hot air at $250^{\circ} \mathrm{C}$ in an oven, both resulting in nearly the same physical sensation and instrument reading for about the same exposure time. One last observation involved contact with cold surfaces rather than heated ones. Since the same theoretical aspects apply and because the electronic system and digital indicator can function in a reverse direction, the overall system might be used to measure human sensibility and exposure or contact hazard in frigid environment applications. Fig. 21 is a photograph of the packaged experimental instrument and probe.

The project was initiated by the former Bureau of Product Safety of the Department of Health, Education and Welfare; the bureau was recently transferred to the Consumer Product Safety Commission. The author wishes to thank Dr. Y. C. Wu of NBS for making available his study material and numerous references on the subject of the hazards in human contact with heated surfaces. The assistance of other members of the staff deserve credits: K. F. Plitt, for his valuable suggestions in the choice of materials; H. D. Kratz, for his efforts in modeling the mechanical desions of the instruments' probe; P. J. Tobin, for the numerous drawings that are included in this report and to Rosemary Massengill for her untiring typing work in the preparation and restructuring of the manuscript. 
Derivation of Function in Fig. 15, referred to in Section 5.1

The interface or contact temperature between two masses brought into contact can be predicted by a formula derived from fundamental heat-flow theory. The contact temperature $T_{c}$, measured by the instrument can be stated as [5]

$$
T_{c}=T_{h}-\frac{T_{h}-T_{p}}{1+\sqrt{\lambda_{h} / \lambda_{p}}}
$$

where $T_{h}$ is the temperature of the heated surface contacted by the probe whose own initial temperature is $T_{p}: \lambda_{h}$ and $\lambda_{p}$ are the thermal inertias of the heated mass and the probe respectively. Various types of glass can be used for $\lambda_{h}$; a suggested standard reference is Corning type 7940 fused-silica. The data sheet supplied with the glass has extensive information concerning the thermal properties of the material, including the specific heat, thermal conductivity and density. The thermal inertia $\lambda$, the product of these three factors, can be readily calculated. The units given are in calories, centimeters, grams, seconds and degrees celsius; these units are convenient since they are the ones used most in both the literature and in commercial product data sheets ( 1 calorie equals 4.18 joules, approximately.) At $50^{\circ} \mathrm{C}$, Corning 7940 glass has a specific heat $c$, of $0.18 \mathrm{cal} / \mathrm{gm}^{\circ} \mathrm{C}$ i 3 it has a thermal conductivity $\mathrm{k}$, of $3.3 \mathrm{x} 10^{-3}$ cal $\left\langle\mathrm{s} \mathrm{cm}{ }^{\circ} \mathrm{C}\right.$; the density $\mathrm{P}$, is $2.2 \mathrm{gm} / \mathrm{cm}^{3}$. The calculated thermal inertia $\lambda_{\mathrm{h}}$ is $1.3 \mathrm{x}$ $10^{-3^{2}} \mathrm{cal}^{2} / \mathrm{s} \mathrm{cm}$. $\mathrm{c}^{2}: \lambda=\mathrm{kc} \rho$. The thermal inertia diffusivity $\alpha$, is important in the calculation of temperature at various skin depths with contact time. For corning the calculated diffusivity is $\alpha=k / c \rho$; or $8.3 \cdot 10^{-3} \mathrm{~cm}^{2} / \mathrm{s}$,

With regards to the RTV silicone rubber compound in the probe, its thermal inertia $\lambda$, was calculated from the data sheet information supplied with the Eccosil 4952 material and found to be $1.7 \times 10^{-3} \mathrm{cal}^{2} / \mathrm{s} \mathrm{cm}^{\circ} \mathrm{C}^{2}$. This value lies ideally between the extremes of the values for thermal inertia of human skin.-3 The most accepted documented

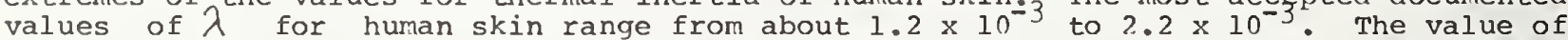
thermal inertia for the RTV probe material may vary from one hatch to another by perhaps 10\%; however the accuracy of measurement hy the instrument does not suffer in direct proportion. Expression (1) shows that the thermal inertia factors do not have a one-to-one relationship with the value of measured $T_{c}$; - Section 6 .

\section{APPENDIX B}

Derivation of Functions in Fig. 16 referred to in Section 5.2

The internal temperature distribution in a solid at an initial temperature To can be calculated from the following expression which is a solution to the Fourier heat- 
flow equations assuming one-dimensional flow. The temperature $T b$, at depth $x$ from the interface and at time $t$ from the instant of contact is given by [5]

$$
T_{b}-T_{c}=\left(T_{p}-T_{c}\right) \operatorname{erf}\left(x / 2 \sqrt{\alpha_{p} \cdot t}\right.
$$

where $\mathcal{X}_{p}$ is the thermal diffusivity of the probe or finger in contact with the source of heat and

$$
\operatorname{erf}(y)=(2 / \sqrt{\pi}) \cdot \int_{0}^{y} e^{-v^{2}} d v
$$

is the error function, a tabulated integral; a convenient list of values is given in Table 2. If the diffusivity is given in $\mathrm{cm}^{2} / \mathrm{s}$ as is the usual case in material data sheets, than $x$ is in centimeters and $t$ is in seconds. This corresponds to the dimensions shown in Appendix A. Expression (2) is useful in establishing the temperature in the dermal region of human skin for a stated contact temperature, contact time and penetration depth. Of immediate interest is the use of the formula for determining the temperature gradient in the probe. A series of curves were generated using four different values of depth measured from the probe face to the thermocouple junction and corresponding to different depths of the dermal layer in human skin. The results are plotted in Fig. 16.

\section{References}

1. Wu, Y.C., "Material Properties Criteria for Thermal Safety", Journal of Materials, JMISA, Vol. 7, No. 4, December 1972, pp 573-579.

2. Marzetta, L. A.," "A Thermesthesiometer - An Instrument for Burn Hazard Measurement", to be published in outside journal.

3. Stoll, A. M. in Advances in Heat Transfer, Vol. 4, J. P. Hartnell and T. F. Irvine, Jr., Eds. Academic Press, New York, 1967.

4. Henriques, F. C. and Moritz, A. R., American Journal of Pathology, Vol. 23, 1947, pp. 531 and 695.

5. Carslaw, H. S. and Jaeger, J. C., Conduction of Heat in Solids, 2nd ed. Clarendon Press, Oxford, 1959. 
Table 1

List of Components and Materials

Resistors

All resistors are $1 / 4$ watt, 28 tolerance, tin-oxide film type except where noted; all values stated in ohms.

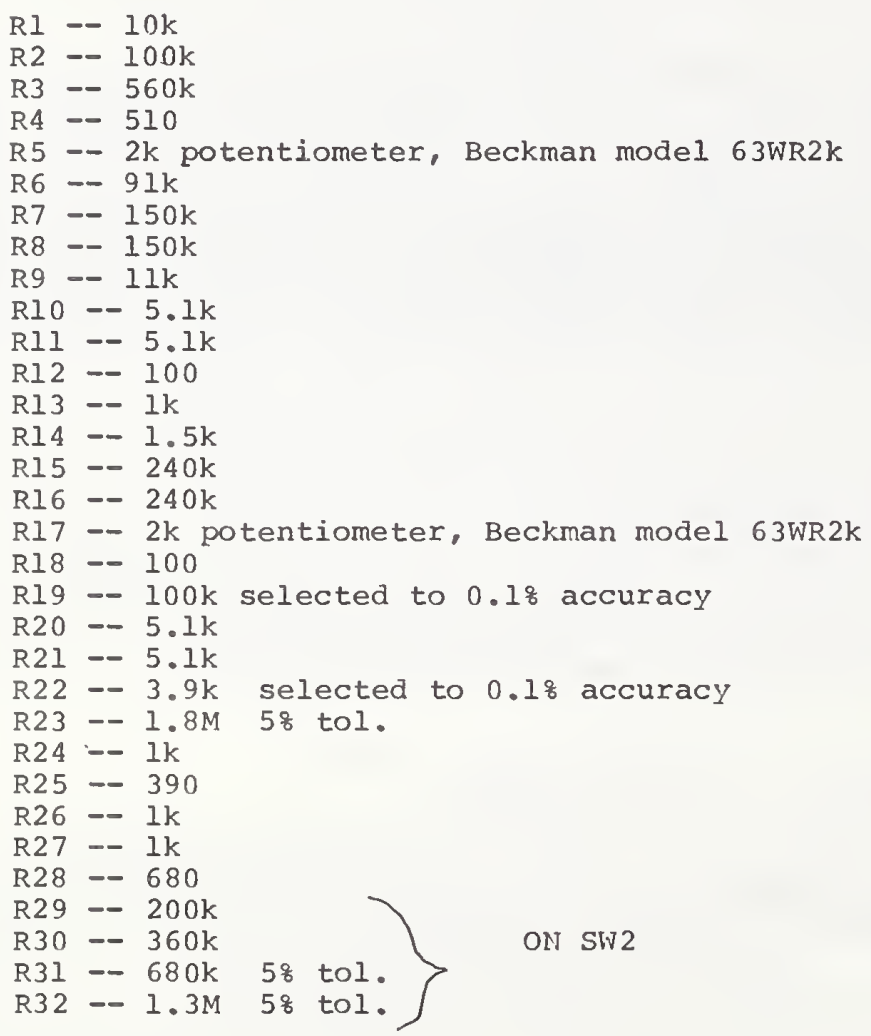

Capacitors

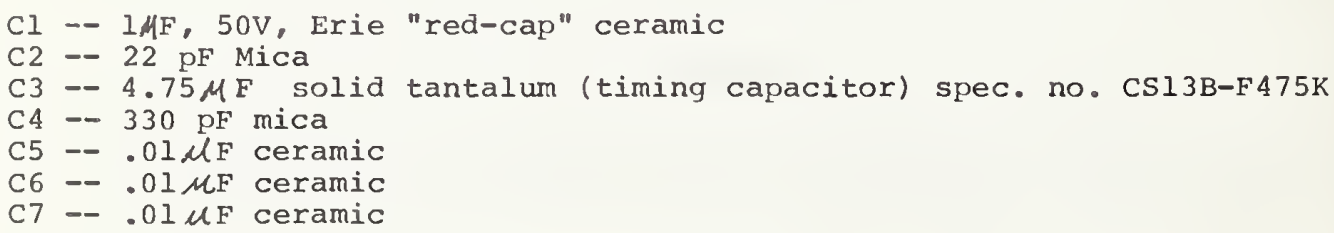



CRI -- 1N3064 diode
CR2 -- IN3064 diode
CR3 -- IN4729 zener diode $3.6 \mathrm{~V}$
CR4 -- IN4729 zener diode $3.6 \mathrm{~V}$
CR5 -- LED, Fairchild type FLV-I00
CR6 -- LED, Fairchild type FLV-100
CR7 -- LED, Fairchild type FLV-100

Ul -- IC, 74121, one-shot multivibrator

U2 -- IC, Signetics NE555V, timer, dual inline package

U3 -- IC, 74107, J-K Flip-Flop

Al -- IC, operational amplifier National Semiconductor, model LH0042CH

A2 -- IC, operational amplifier. Analog Devices Model AD504K

Q1 -- transistor, 2N519I

Q2 -- transistor, 2N3638, PNP General Purpose

Q3 -- transistor, 2N3643, NPN General Purpose

\section{Switches and Connectors}

SWI -- miniature power switch

SW2 -- miniature rotary switch, Alco type MRA-2-5S

SW3 -- miniature push button switch, normally open

Pl -- AMP Corp. AMPMODU pin posts, part no. 85931-6

P2 -- AMP Corp. AMPMODU cable connector, no. 1-86256-7 and contact no. 86015-2 plus crimping tool no. 90202-2

P3 -- probe cable plug, Amphenol no. 126-195

p4 -- panel socket. Amphenol no. 126-198

P5 -- power line filter socket and line cord, Corcom EMI filter no. 185, line cord no. 80-1255 
Digital Panel Meter, 0-100.0 mV, California Instruments type 83330, San Diego, California - also a second source is Analog Devices, model AD2010, physical size is slightly different from previous unit. The digital panel meter must have the following specifications: A full scale range of 0 to 199.9 millivolts dc; $B C D$ output line, positive true logic, for initiating the timing sequence at the 40 millivolt crrossing; external hold line, logic 0 hold, for "freezing" the contact temperature reading; an internal triggered conversion rate of at least 4 conversions per second.

PSl -- dc to dc converter module, $5 \mathrm{~V}$ to $15 \mathrm{~V}$, Semiconductor Circuits Co.. model DD5-2.15.25, also L-TRON, type LPA, 5-2.15-30, L-TRON Co., Fairfax, Virginia for a second source.

PS2 -- power supply module, 5V, 1 ampere with unregulated 8 to 10 volt tap, Semiconductor Circuits Co., type P.C. card no. 1.5, 1000, also I-TRON type $L T-1.5,1000$ for a second source.

Printed Circuit board spring terminals for digital IC modules, Walden/Molex IC Soldercon terminals no. 05-30-0001.

Printed Circuit board spring sockets for IC op amps, AMP Co., part no. 50462-8.

Resistance thermometer for probe, type DN-100, RDF Corp., Hudson, N.H.

Thermocouple ribbon wire, Chromel and Alumel, three inch strips about 0.040 inches wide and 0.003 inches thick; Namac Corp., Framingham, Mass.

Alternate - fine wire thermocouple, Chromel - Alumel, three mil diameter wire with welded ball junction; RDF Corp. or Omega Engineering Corp.

Heater winding resistance wire with insulated coating, \#36 gage, 0.005 inch dia.. 31.7 ohms/foot, Driver Harris Co., Karma type insulation or equivalent.

Six Conductor cable, Alpha Wire Co., no. 1176.

RTV Silicone Rubber compound for probe, ECCOSIL 4952 and ECCOSIL Primer No 33, Emerson and cuming Inc.

Standard Reference Surface: Fused Silica, Code 7940, Optical Grade no. 2, circle - 2-1/2 inch dia., 1/2 inch thick, Corning Glass Co.

Instrument Cabinet, presently under consideration, possible use of cabinet Wamco part no. 6153, special order, W. A. Miller Co., Oquossos, Maine. 
Table 2 Values of erf $(y)$

$\begin{array}{cccccccc}y & \operatorname{erf}(y) & y & \operatorname{erf}(y) & y & \operatorname{erf}(y) & y & \operatorname{erf}(y) \\ 0.00 & 0.00000 & 0.25 & 0.27633 & 0.50 & 0.52050 & 0.75 & 0.71116 \\ 0.01 & 0.01128 & 0.26 & 0.28690 & 0.51 & 0.52924 & 0.76 & 0.71754 \\ 0.02 & 0.02256 & 0.27 & 0.29742 & 0.52 & 0.53790 & 0.77 & 0.72382 \\ 0.03 & 0.03384 & 0.28 & 0.30788 & 0.53 & 0.54646 & 0.78 & 0.73001 \\ 0.04 & 0.04511 & 0.29 & 0.31828 & 0.54 & 0.55494 & 0.79 & 0.73610 \\ & & & & & & & \\ 0.05 & 0.05637 & 0.30 & 0.32863 & 0.55 & 0.56332 & 0.80 & 0.74210 \\ 0.06 & 0.06762 & 0.31 & 0.33891 & 0.56 & 0.57162 & 0.81 & 0.74800 \\ 0.07 & 0.07886 & 0.32 & 0.34913 & 0.57 & 0.57982 & 0.82 & 0.75381 \\ 0.08 & 0.09008 & 0.33 & 0.35928 & 0.58 & 0.58792 & 0.83 & 0.75952 \\ 0.09 & 0.10128 & 0.34 & 0.36936 & 0.59 & 0.59594 & 0.84 & 0.76514 \\ & & & & & & & \\ 0.10 & 0.11246 & 0.35 & 0.37938 & 0.60 & 0.60386 & 0.85 & 0.77067 \\ 0.11 & 0.12362 & 0.36 & 0.38933 & 0.61 & 0.61168 & 0.86 & 0.77610 \\ 0.12 & 0.13476 & 0.37 & 0.39921 & 0.62 & 0.61941 & 0.87 & 0.78144 \\ 0.12 & 0.14587 & 0.38 & 0.40901 & 0.63 & 0.62705 & 0.88 & 0.78669 \\ 0.14 & 0.15695 & 0.39 & 0.41874 & 0.64 & 0.63459 & 0.89 & 0.79184 \\ & & & & & & & \\ 0.15 & 0.16800 & 0.40 & 0.42839 & 0.65 & 0.64203 & 0.90 & 0.79691 \\ 0.16 & 0.17901 & 0.41 & 0.43797 & 0.66 & 0.64938 & 0.91 & 0.80188 \\ 0.17 & 0.18999 & 0.42 & 0.44747 & 0.67 & 0.65663 & 0.92 & 0.80677 \\ 0.18 & 0.20094 & 0.43 & 0.45689 & 0.68 & 0.66378 & 0.93 & 0.81156 \\ 0.19 & 0.21184 & 0.44 & 0.45523 & 0.69 & 0.67084 & 0.94 & 0.81627 \\ & & & & & & & \\ 0.20 & 0.22270 & 0.45 & 0.47548 & 0.70 & 0.67780 & 0.95 & 0.82089 \\ 0.21 & 0.23352 & 0.46 & 0.48466 & 0.71 & 0.68467 & 0.96 & 0.82542 \\ 0.22 & 0.24430 & 0.47 & 0.49375 & 0.72 & 0.69143 & 0.97 & 0.82987 \\ 0.23 & 0.25502 & 0.48 & 0.50275 & 0.73 & 0.69810 & 0.98 & 0.83423 \\ 0.24 & 0.26570 & 0.49 & 0.51167 & 0.74 & 0.70468 & 0.99 & 0.83851\end{array}$


Figure 1 Simplified Drawing of An Experimental Probe

2 Construction Drawing of Probe Core Tube

3 Construction Drawing of Probe Handle

4 Construction Drawing of Probe Body

5 Construction Drawing of Protection Cap For Probe

6 Construction Drawing of Assembly Fixture Parts.

7 Assembly of Probe Parts

8 Sketch of Probe Assembly With Ribbon-Type Thermocouple

9 Schematic Diagram of Probe Wiring

10 Sketch of Probe Assembly With Fine-Wire Type Thermocouple

11 Electrical Schematic Diagram of Complete Instrument

12 Photograph of Printed Circuit Board, Component side

13 Photograph of Printed Circuit Board, Opposite Side

14 Photograph of Component Mounted Board

15 Comparison of Measured and Calculated Values

16 Profiles of Various Skin Depth Temperatures

17 Effect of Thin Plastic Coating on Heated Brass

18 Physiological Response Curve

19 Reading Error Due to Variation In Thermal Inertia Value

20 Reading Error Due to Variation In Controlled Temperature At Probe

21 Photograph of Instrument and Probe 


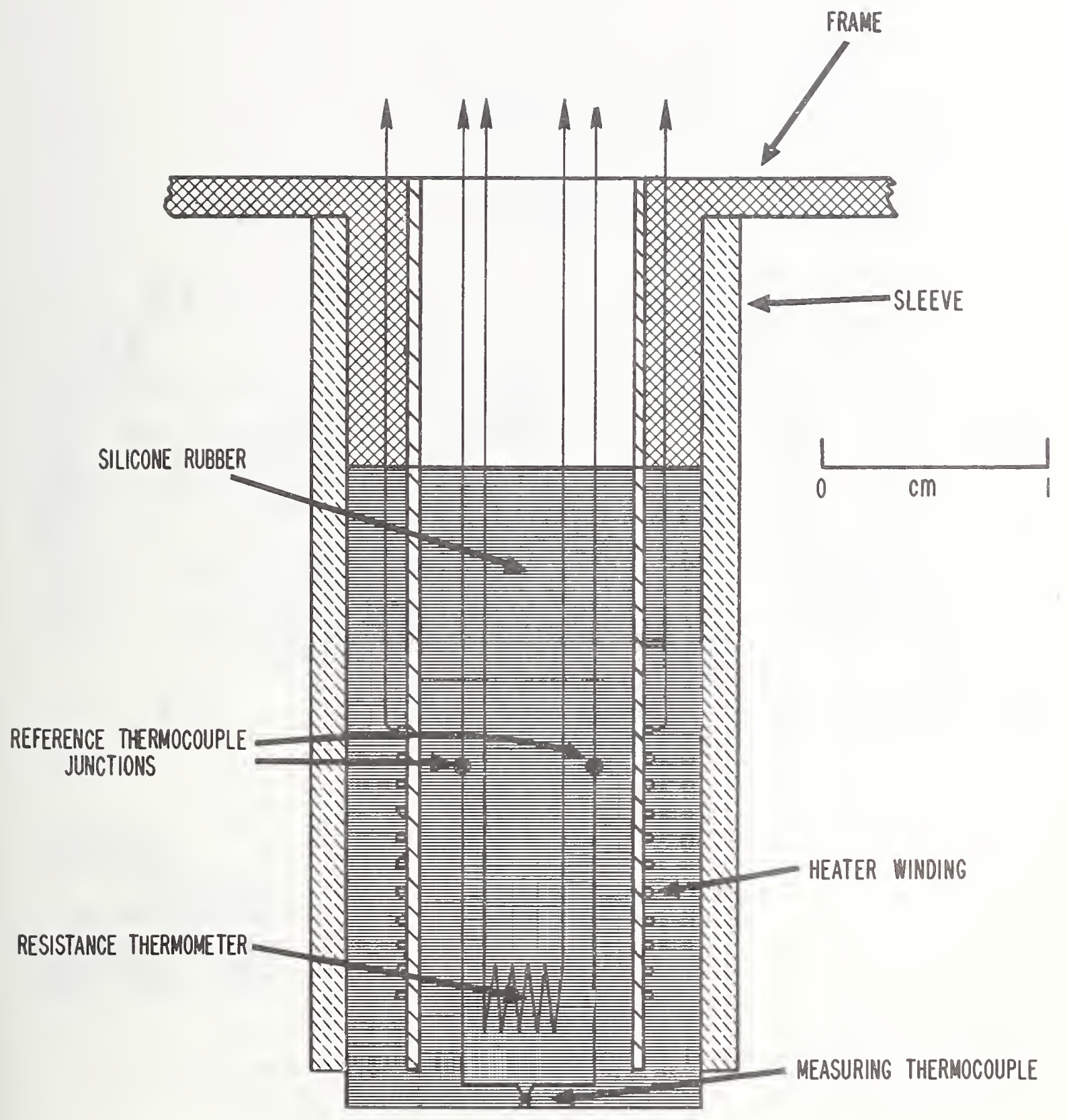

Fig. I Simplified Drawing of an Experimental Probe 

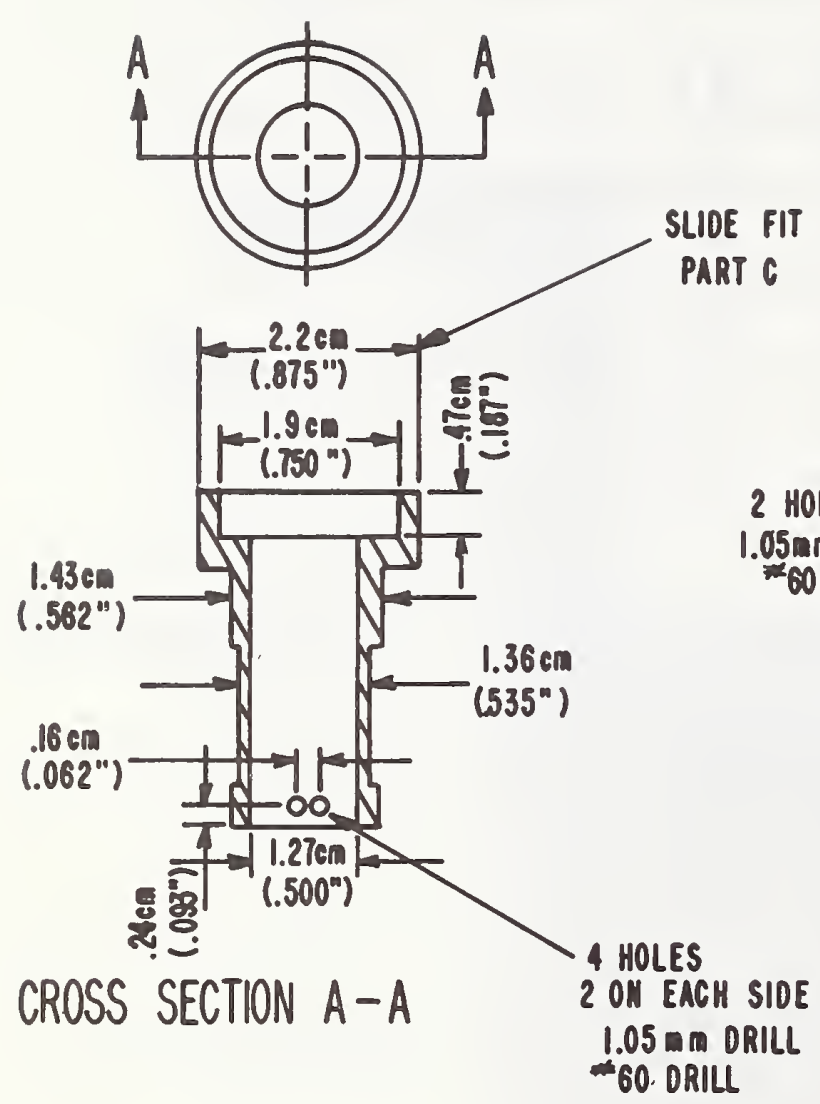

PAPER - BASE BAKELITE
SLIDE FIT IN

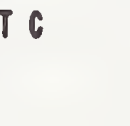

2 HOLES moO DRILL

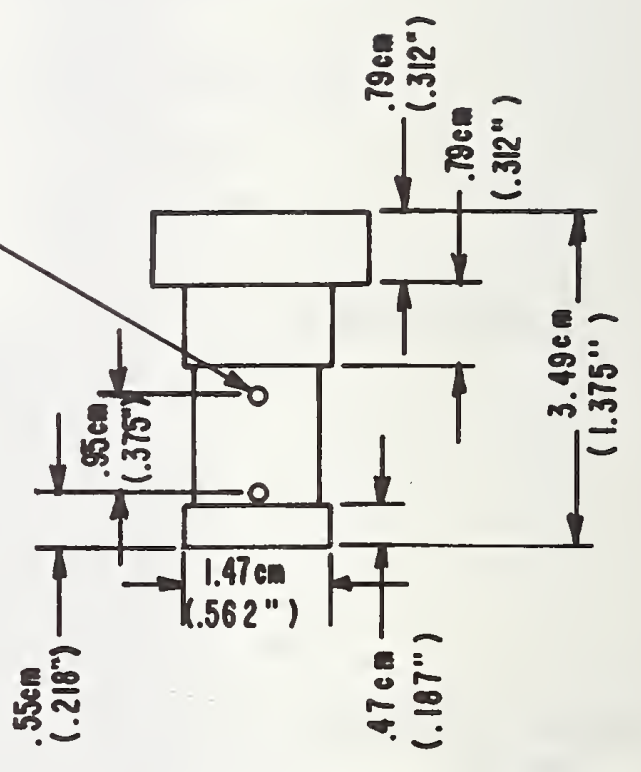

TOLERANCE

$\left( \pm 0.015^{\prime \prime}\right) \pm 0.04 \mathrm{~cm}$

EXCEPT WHERE NOTED

Fig. 2 Construction Drawing of Probe Core Tube (Part A) 


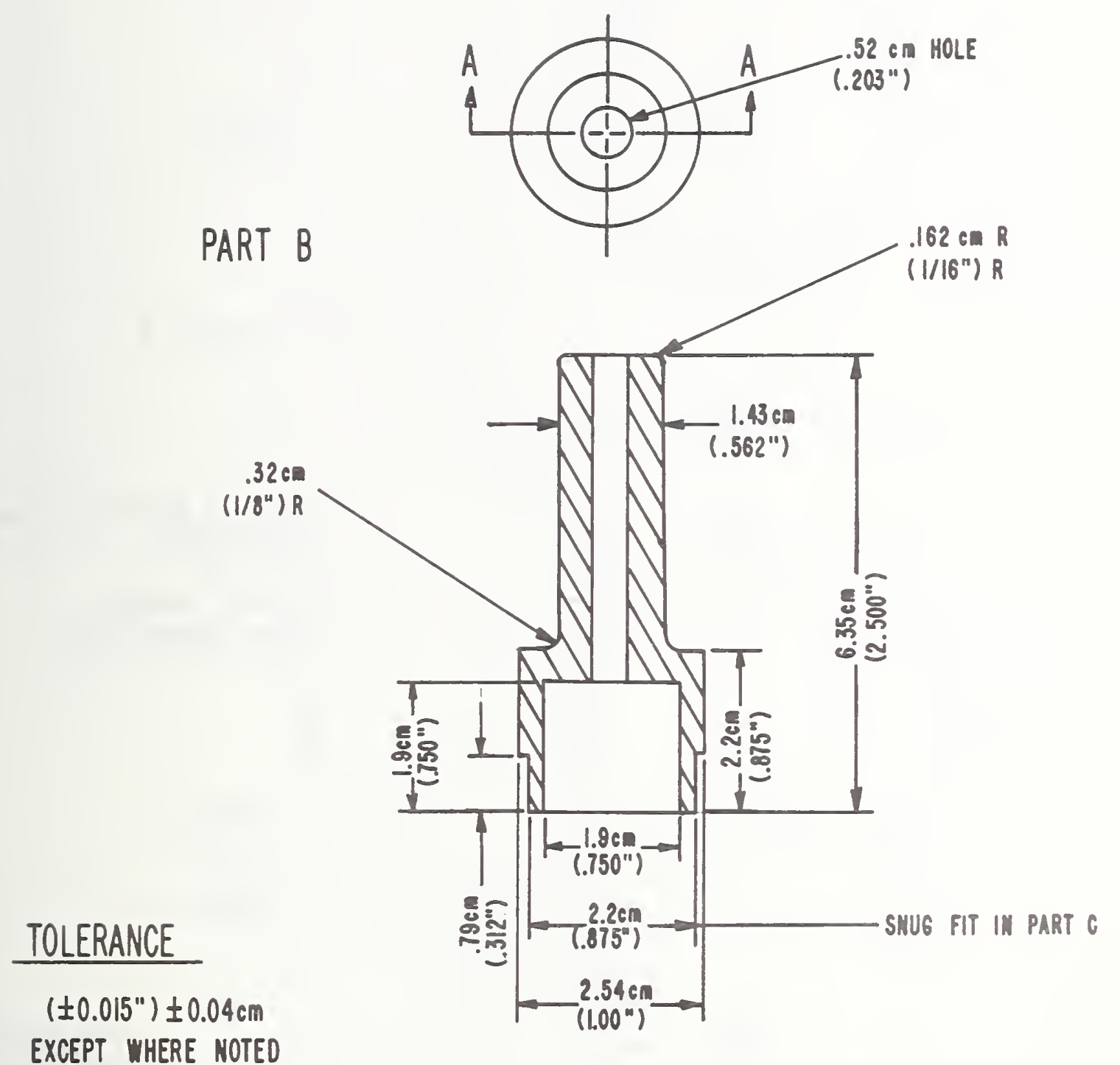

\section{CROSS SECTION A-A \\ NYLON}

Fig. 3 Construction Drawing of Probe Handle (Part B) 

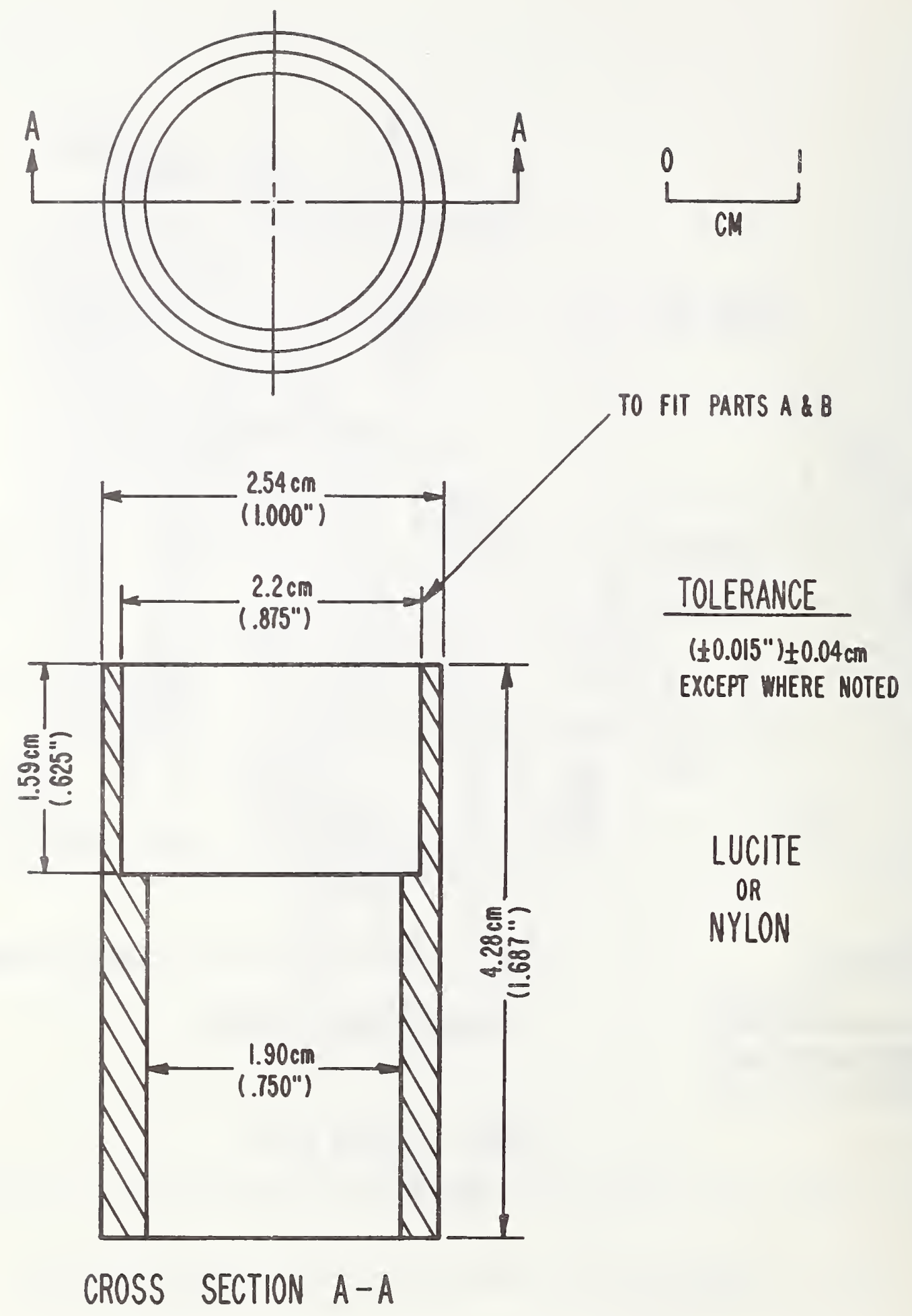

Fig. 4 Construction Drawing of Probe Body (Part C) 


\section{SNUG FIT ON PART C}
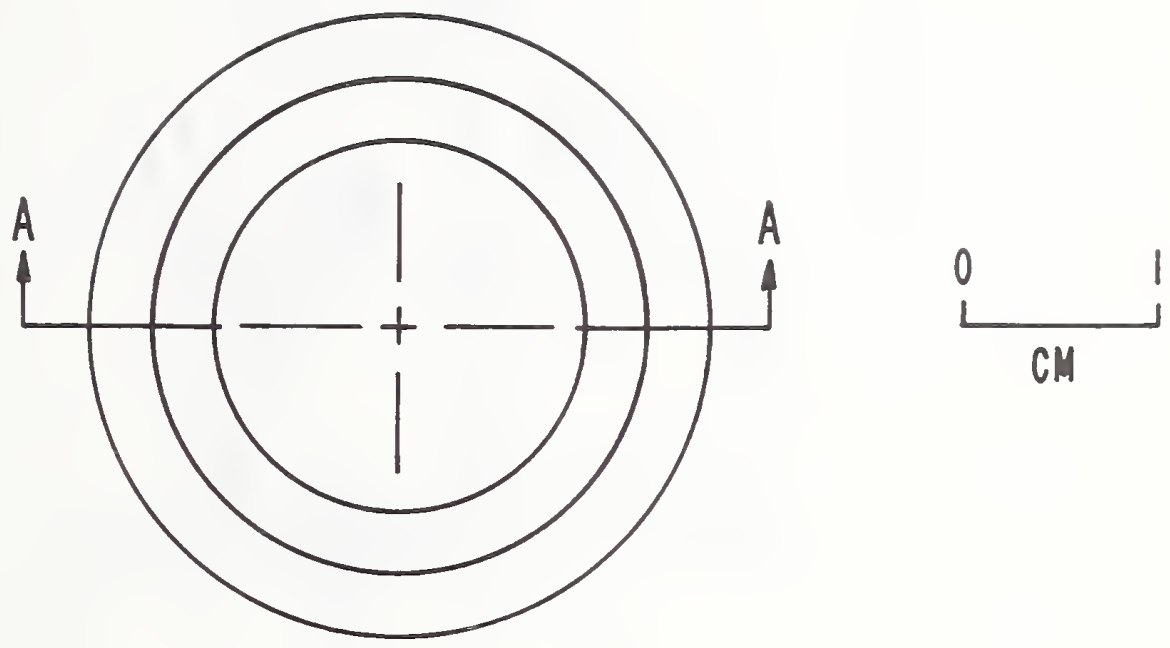

\section{TOLERANCE}

\section{$\left( \pm 0.015^{\prime \prime}\right) \pm 0.04 \mathrm{~cm}$}

EXCEPT WHERE MOTED

\section{NYLON}

Fiq. 5 Construction Drawing of Protection Cap (Part D) 


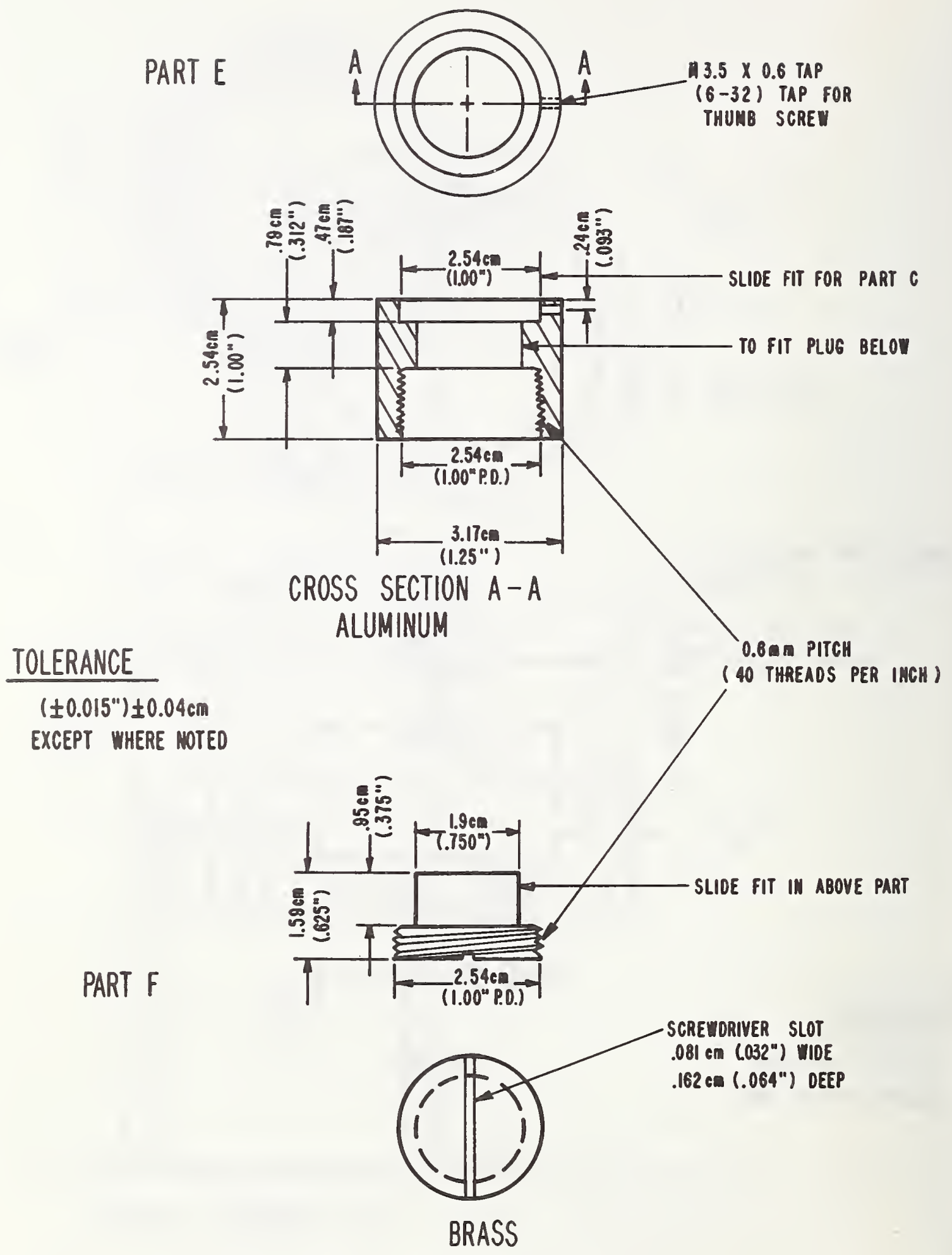

Fig. 6 Construction Drawing of Jig Assembly Fixture Parts For Casting - Not Part of the Probe (parts $E$ and F) 


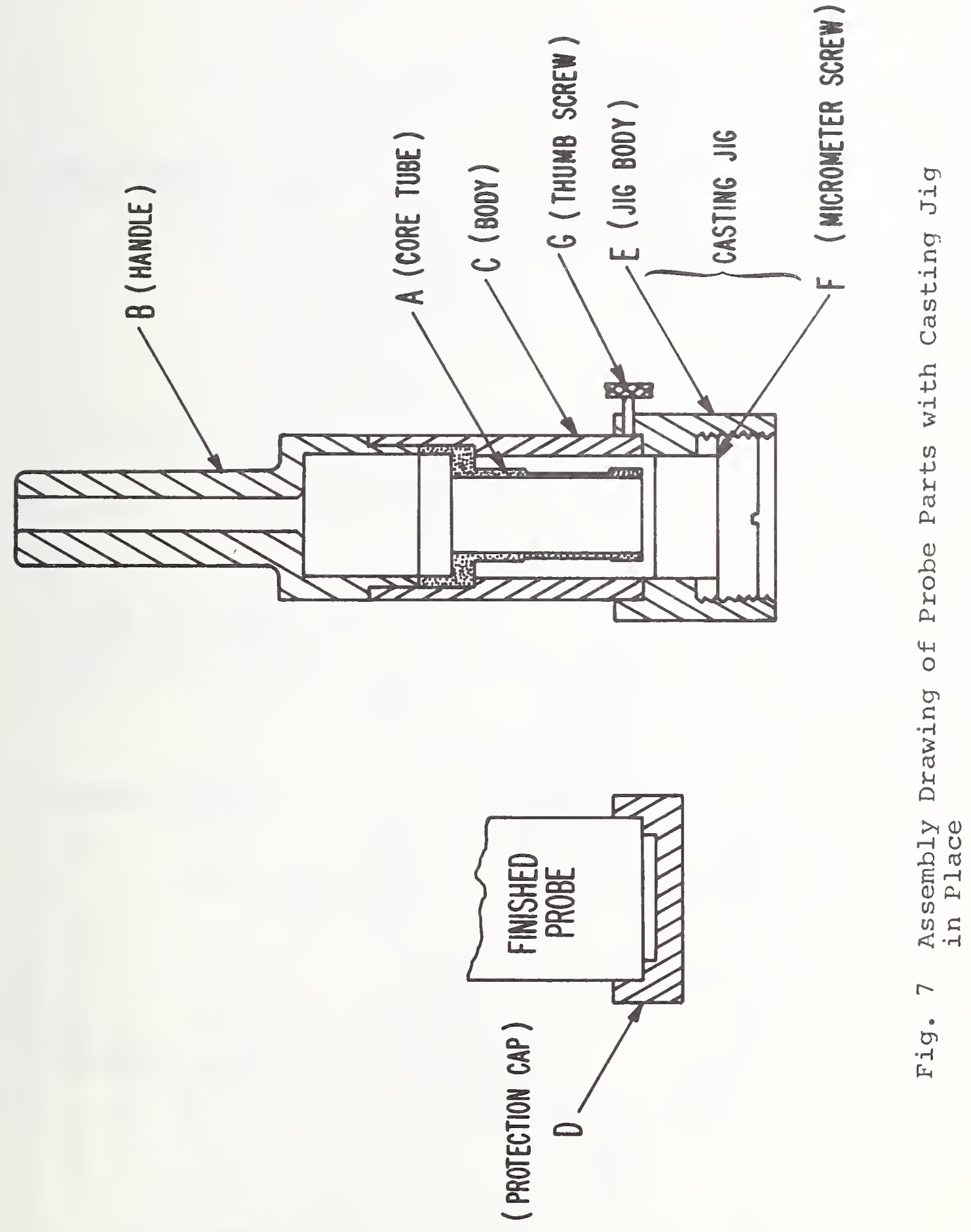




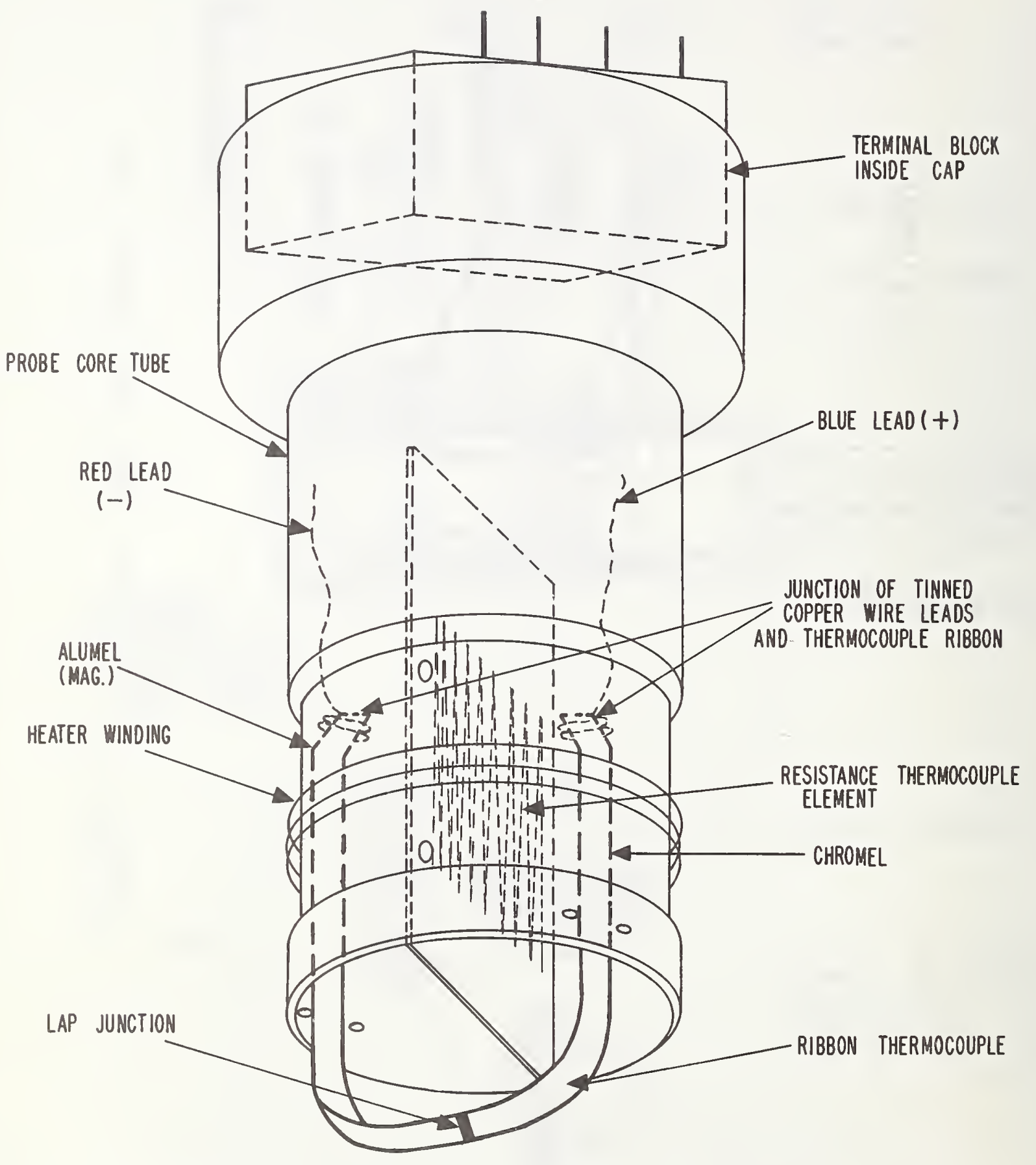

Fig. 8 Sketch of Probe Assembly with Ribbon-Type Thermocouple 

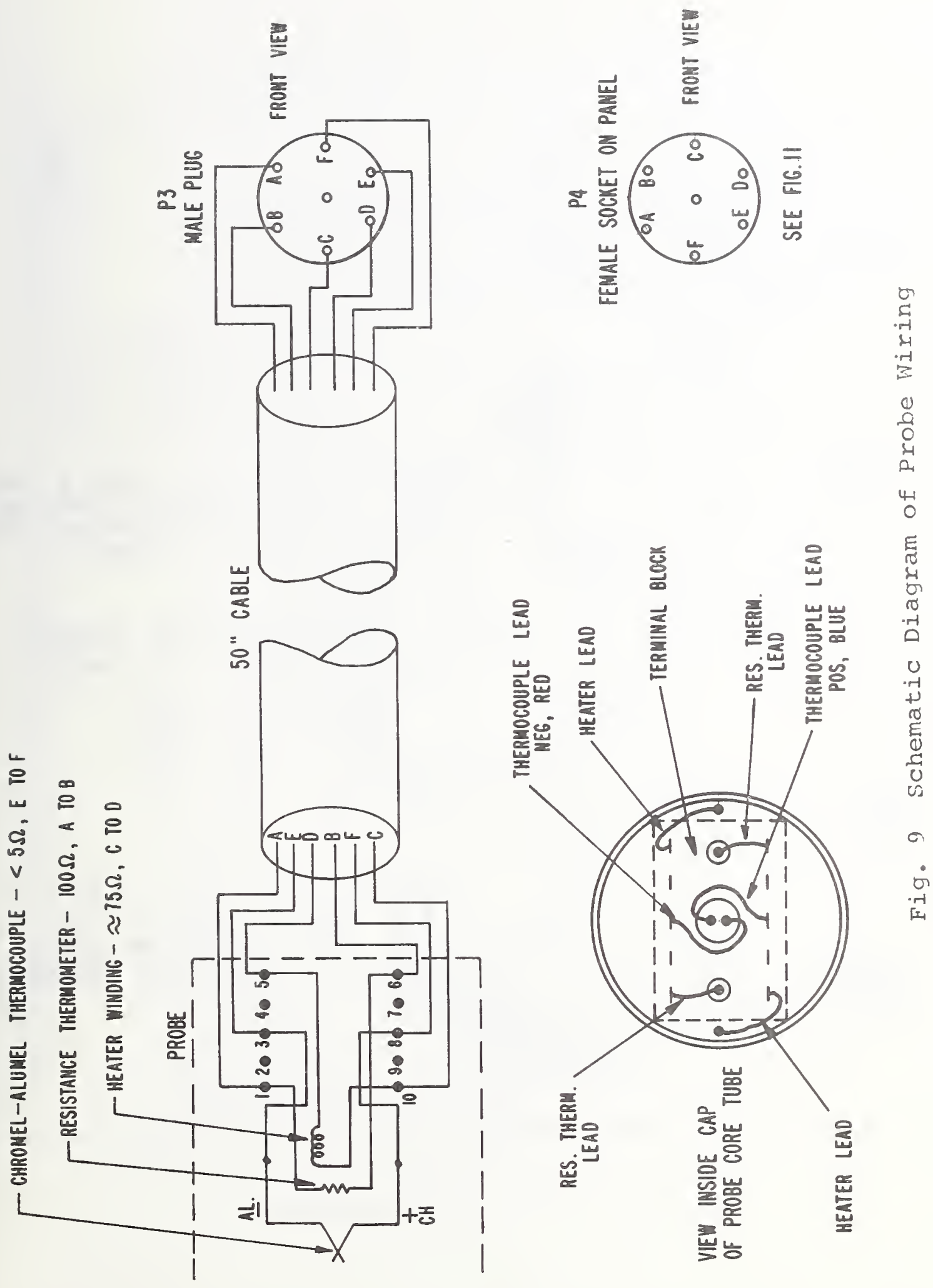


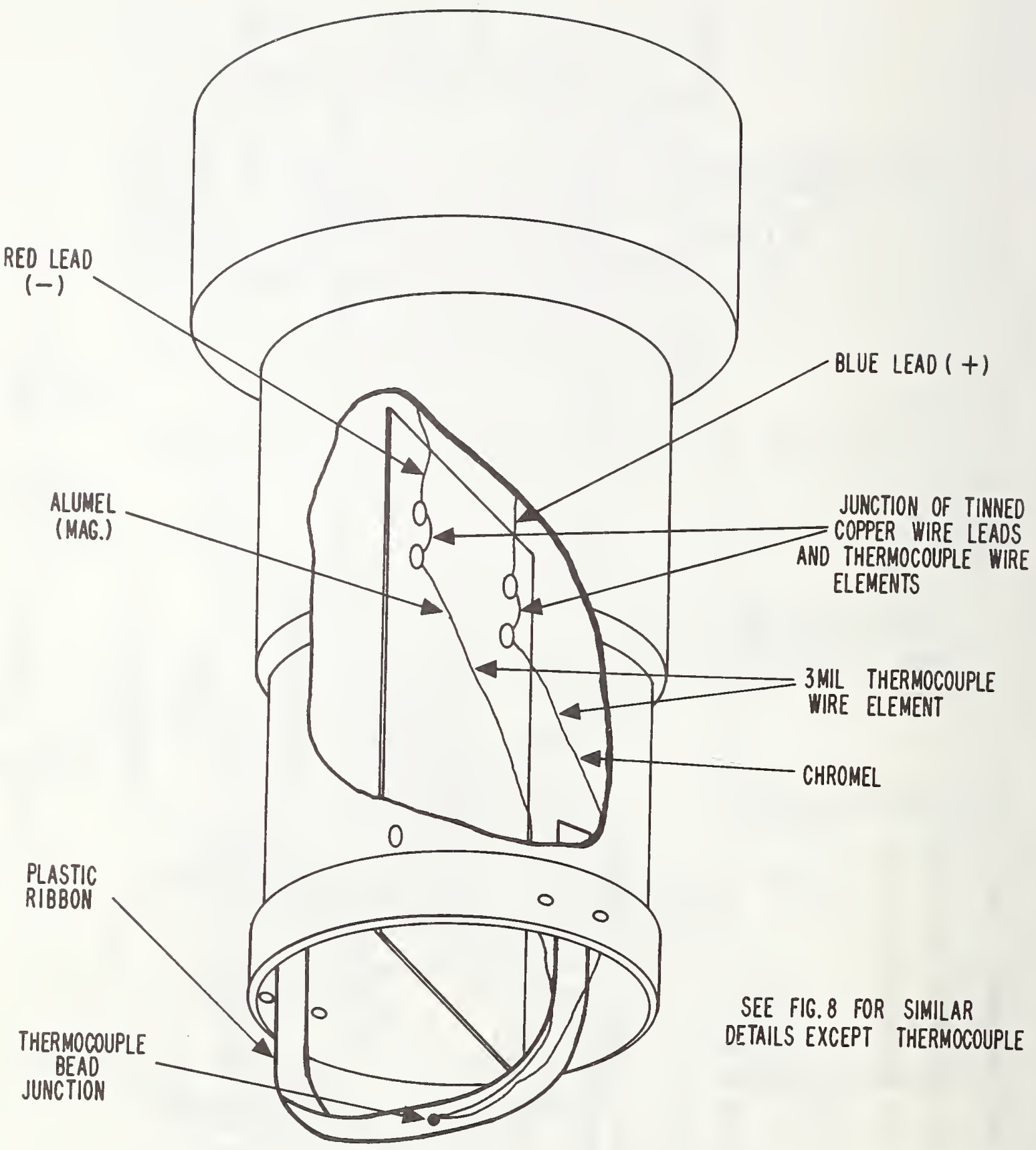

Fig. 10 Sketch of Probe Assembly With Fine-Wire Thermocouple 


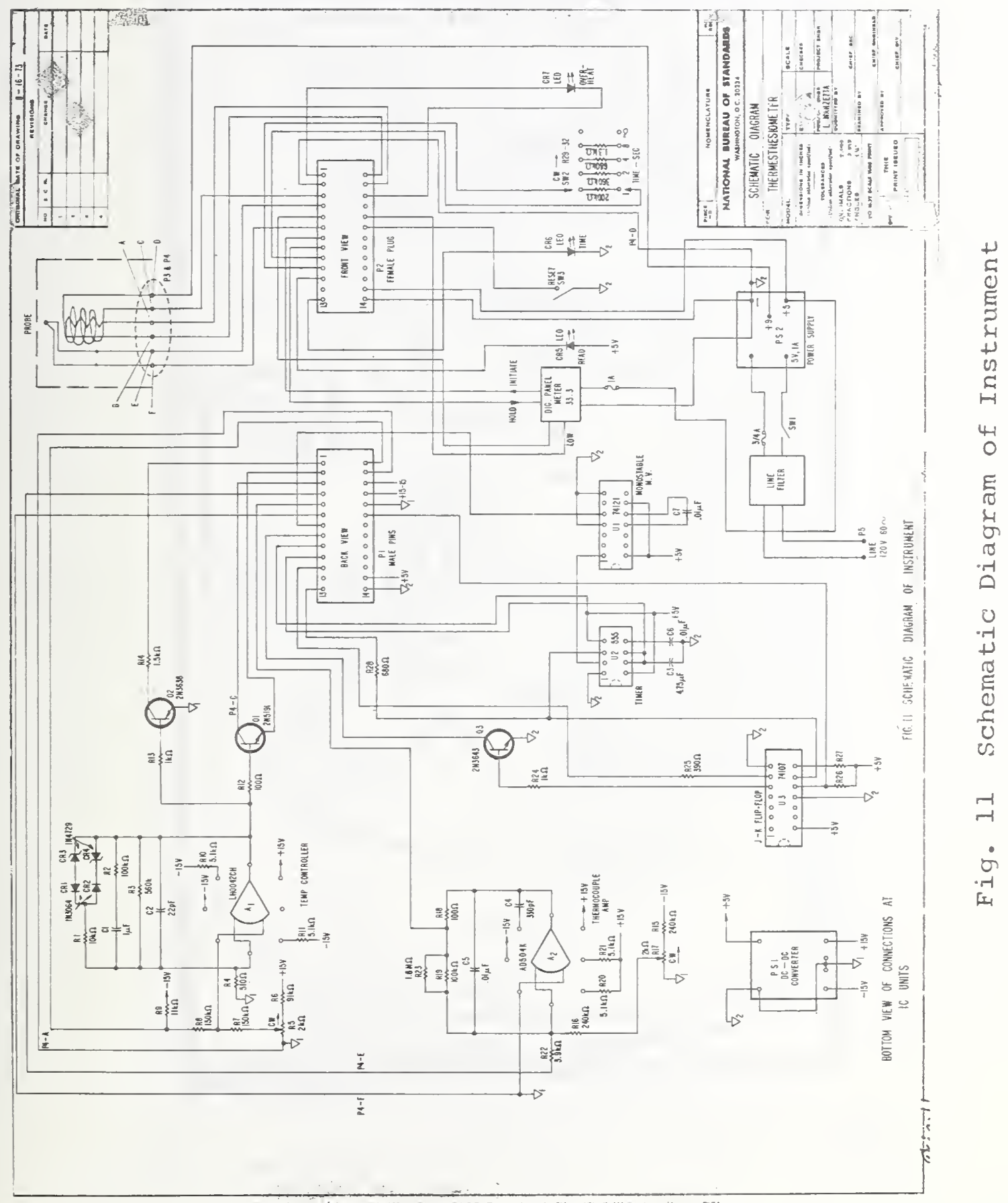




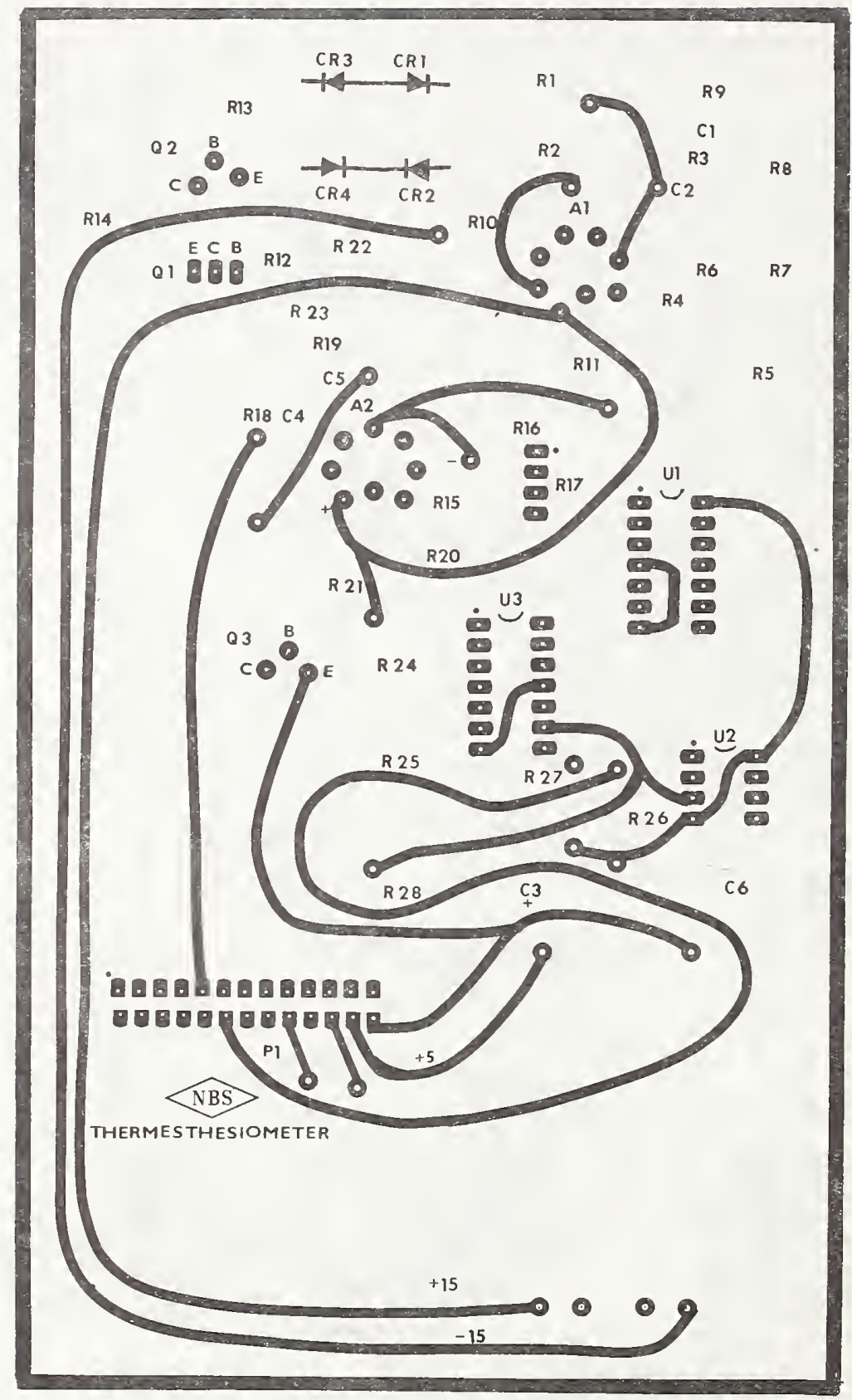

Fig. 12 Printed Circuit Board, Component Side 


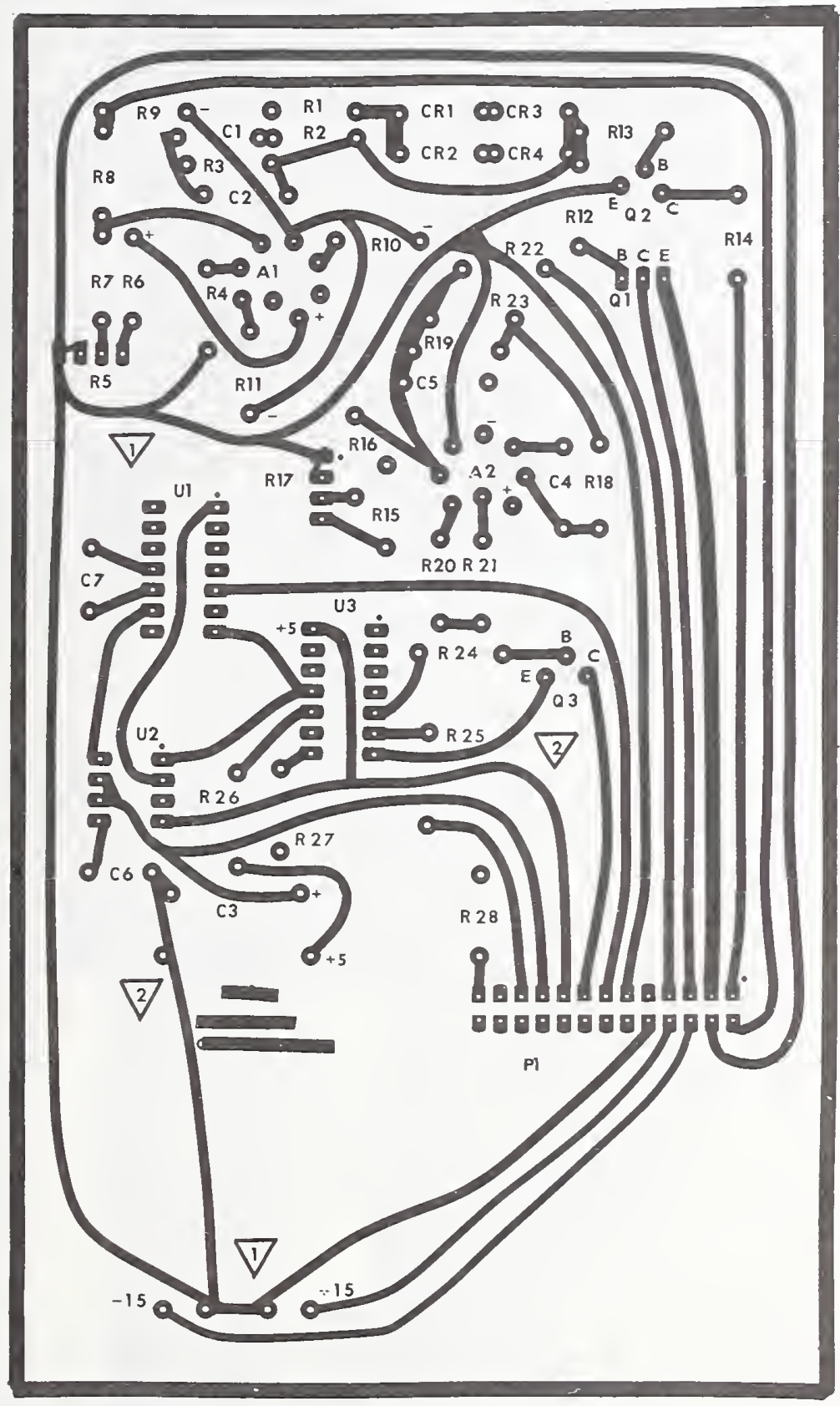

Fig. 13 Printed Circuit Board, Opposite Side 


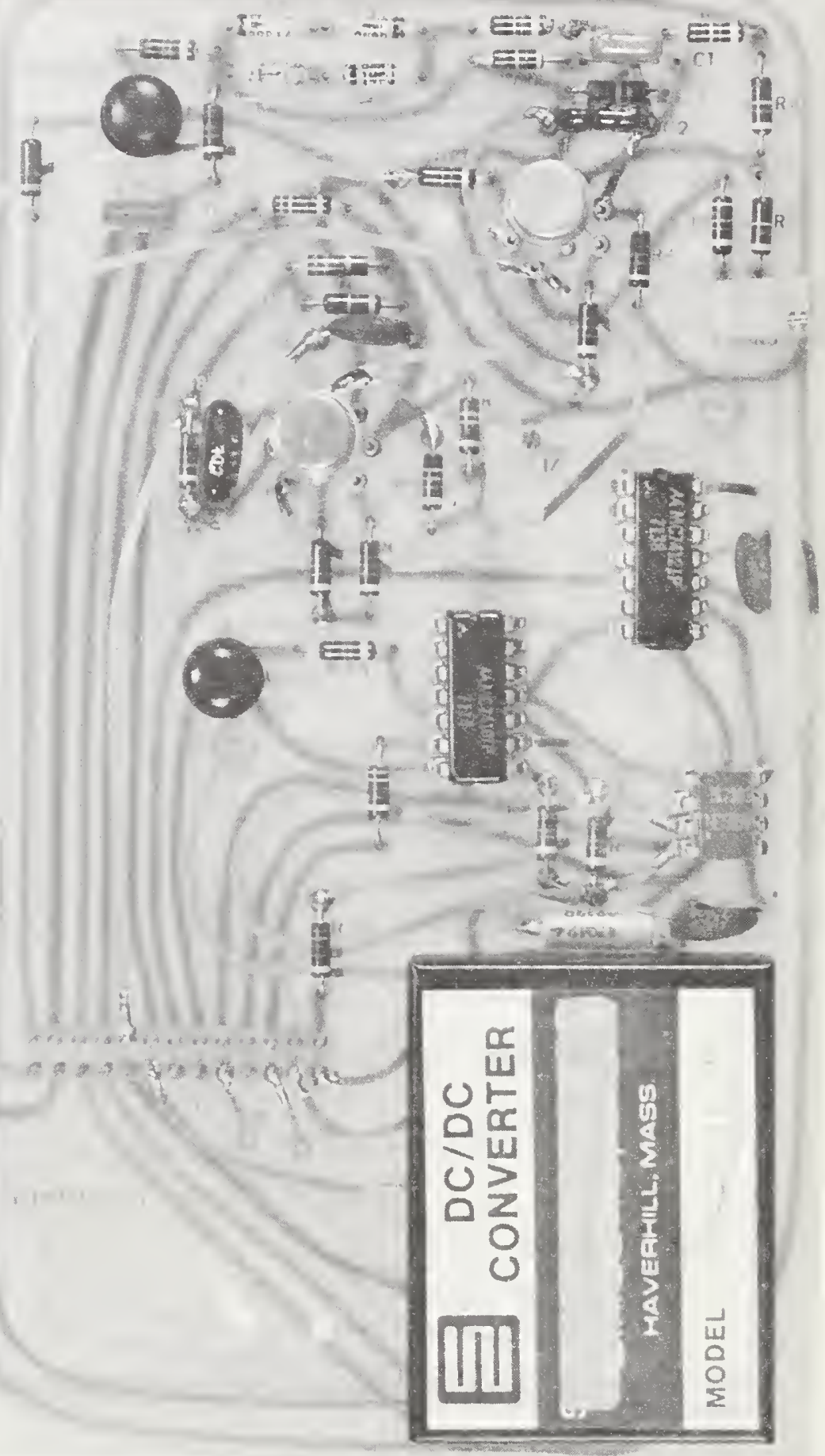

Fig. 14 Component Mounted Board 


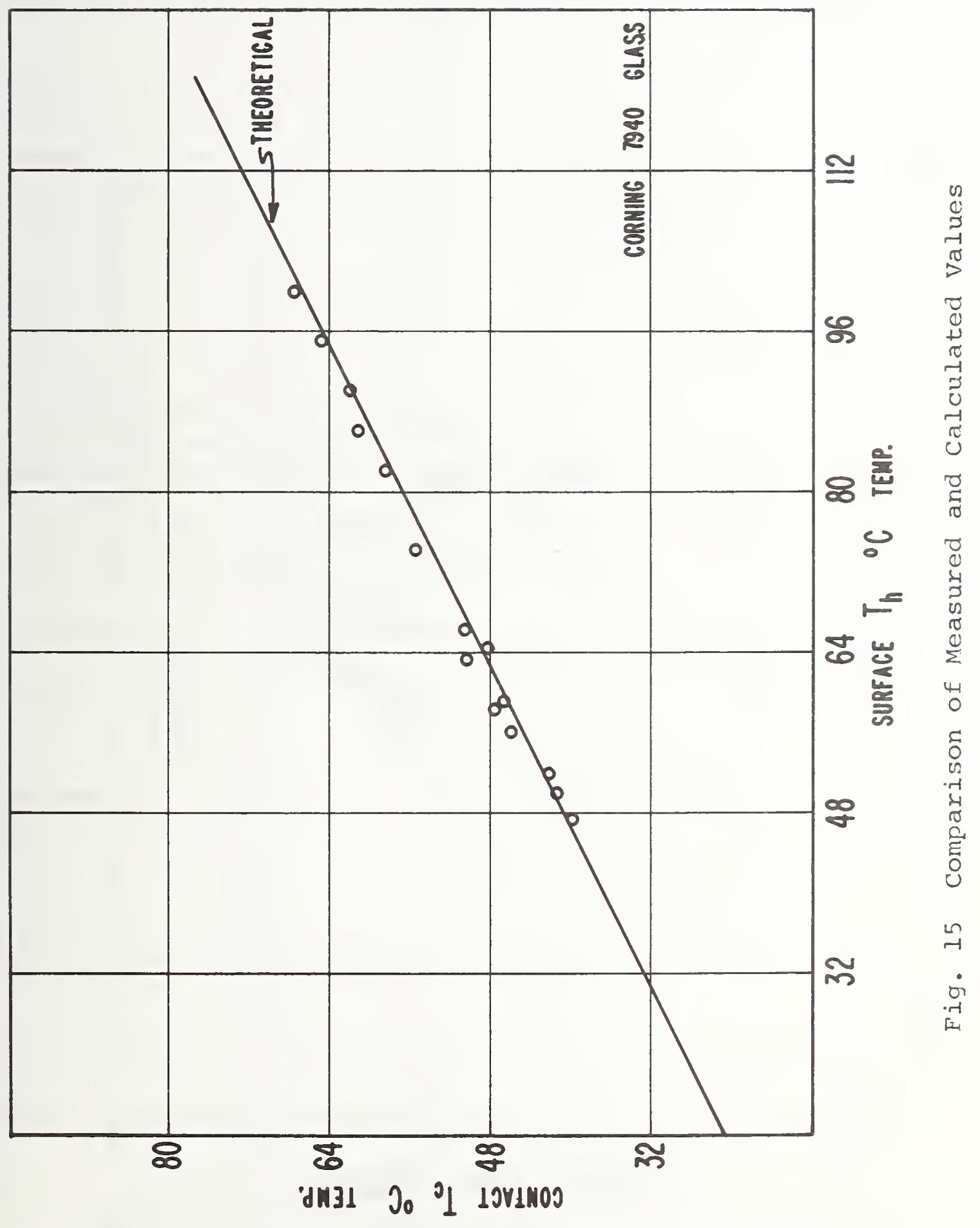




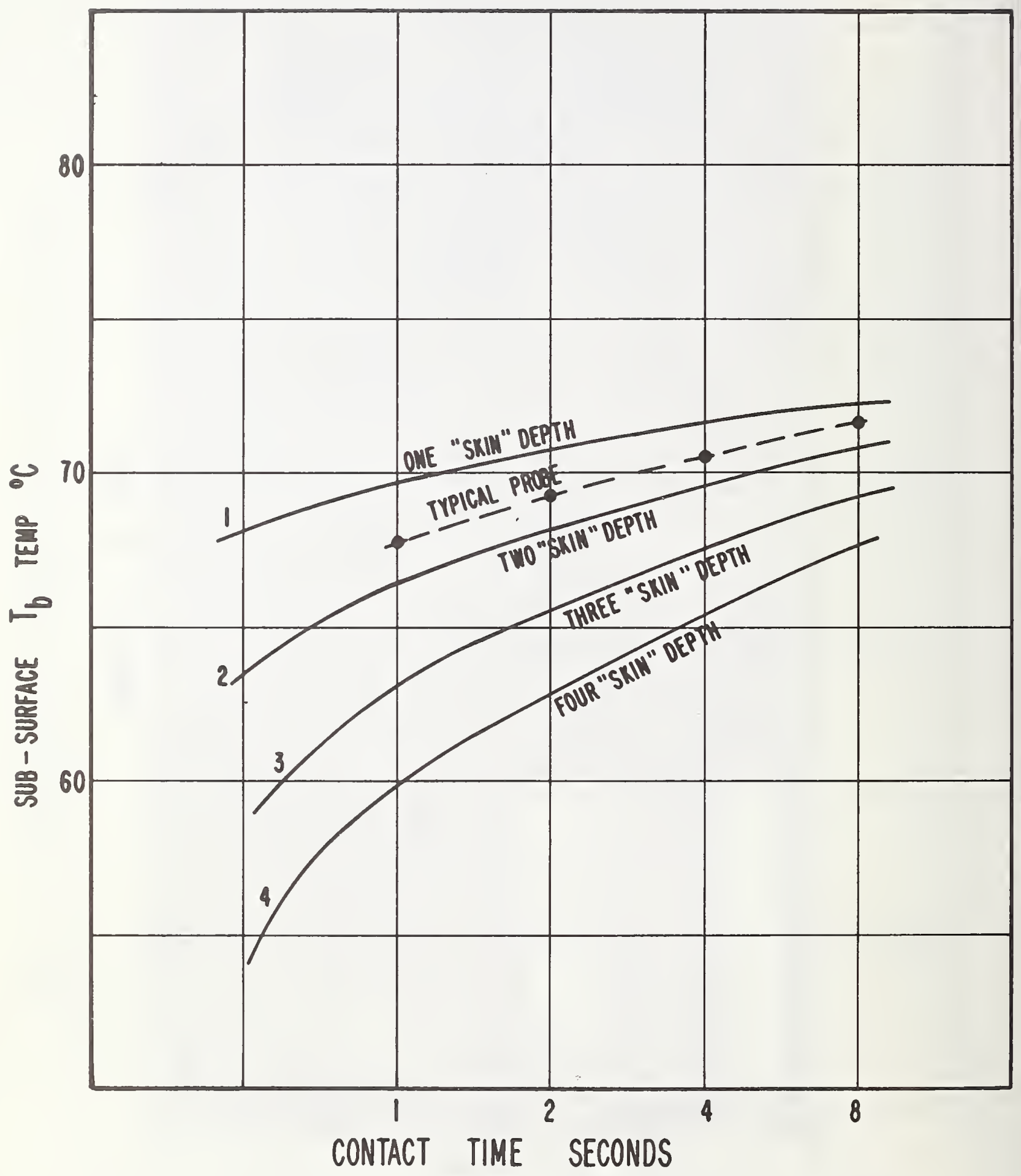

Fig. 16 Profiles of Various Skin Depth Temperatures 


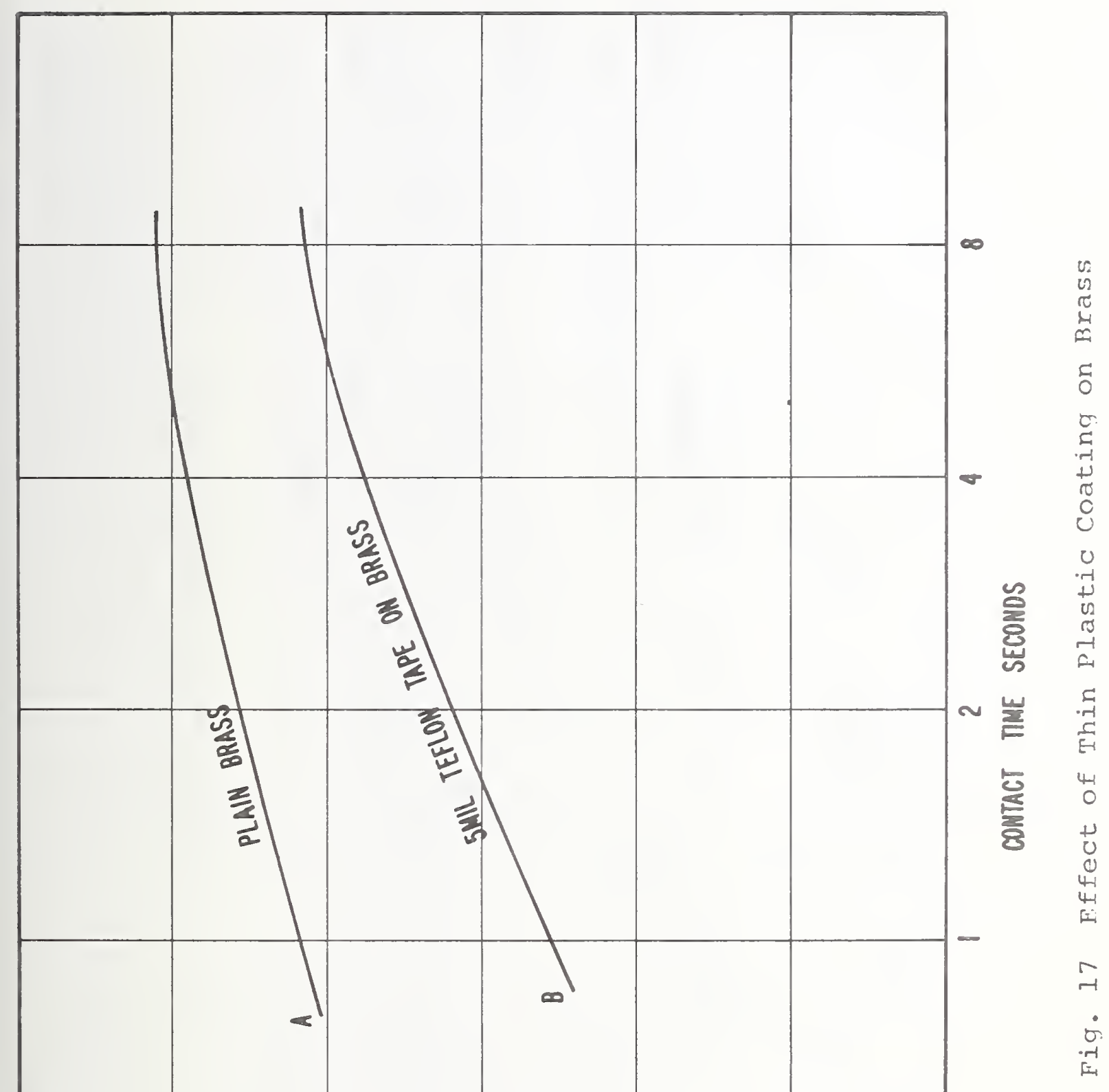




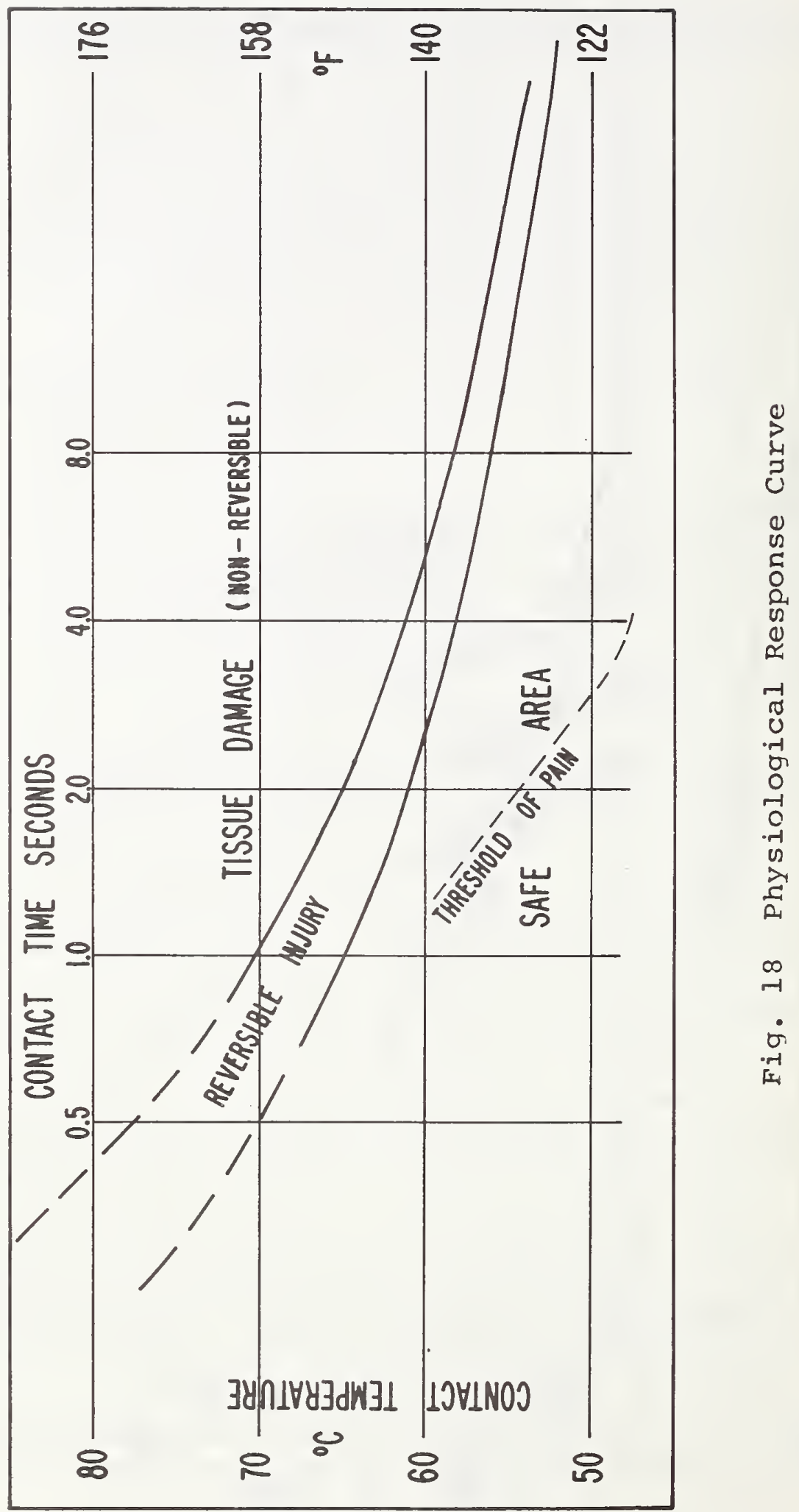




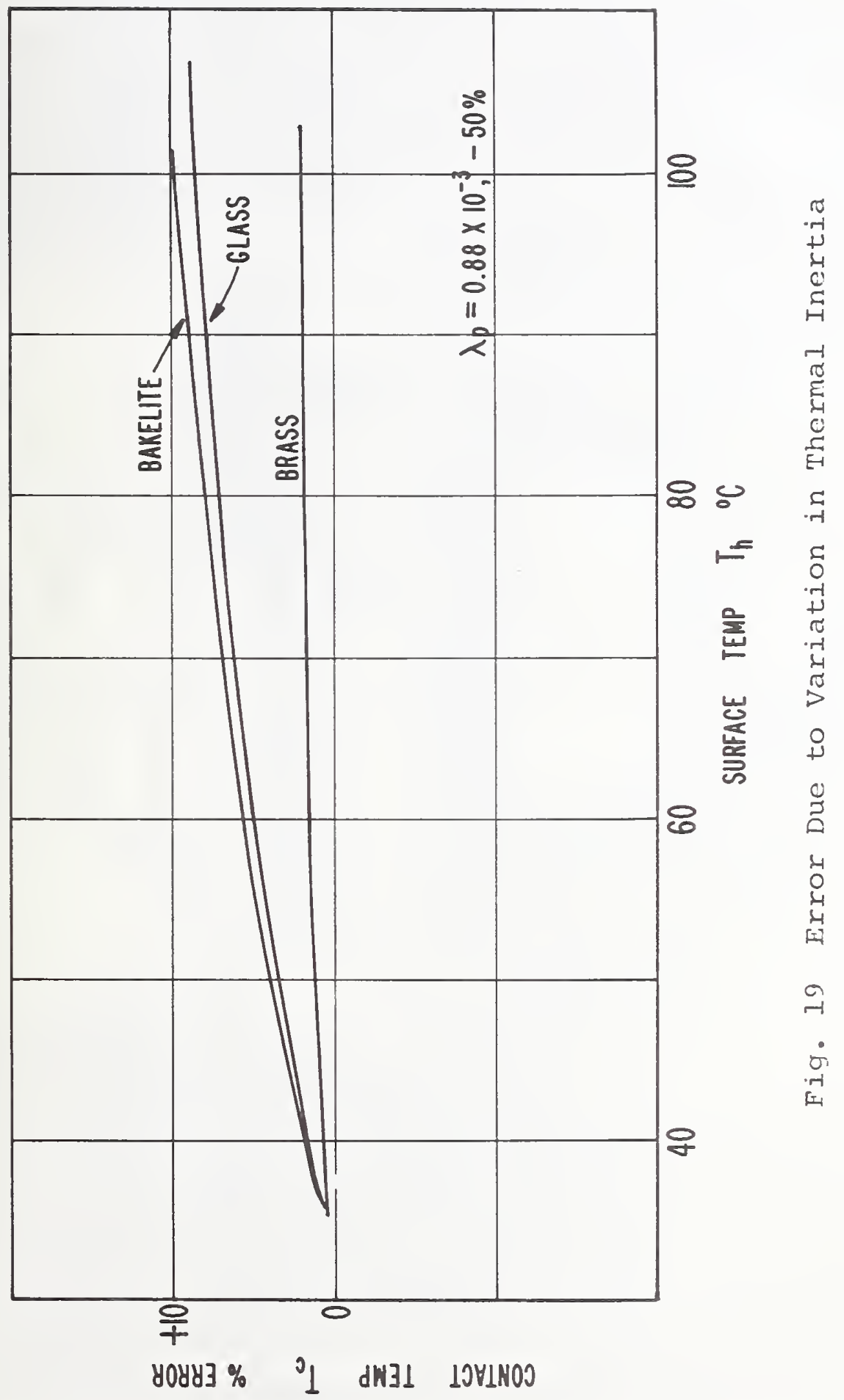




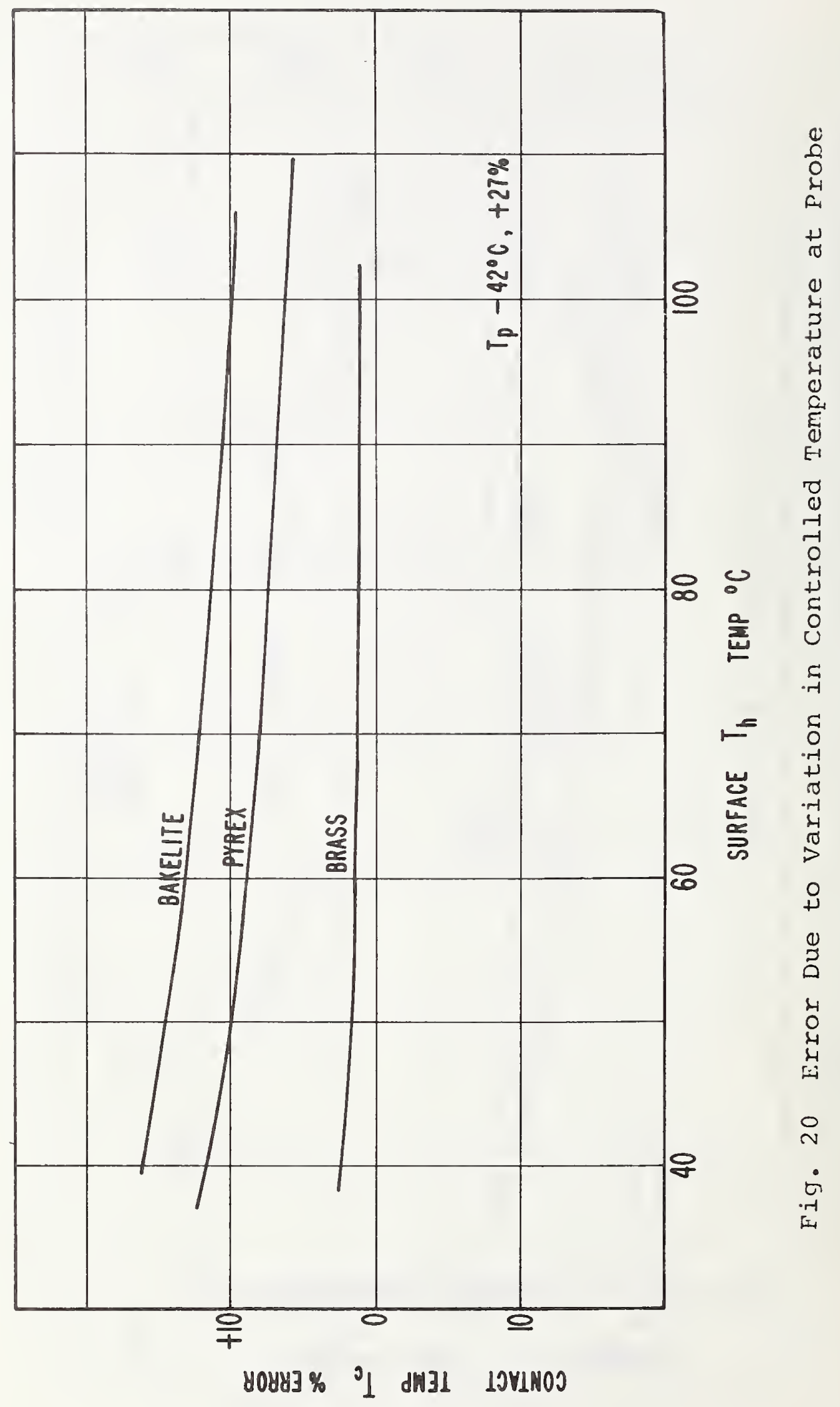




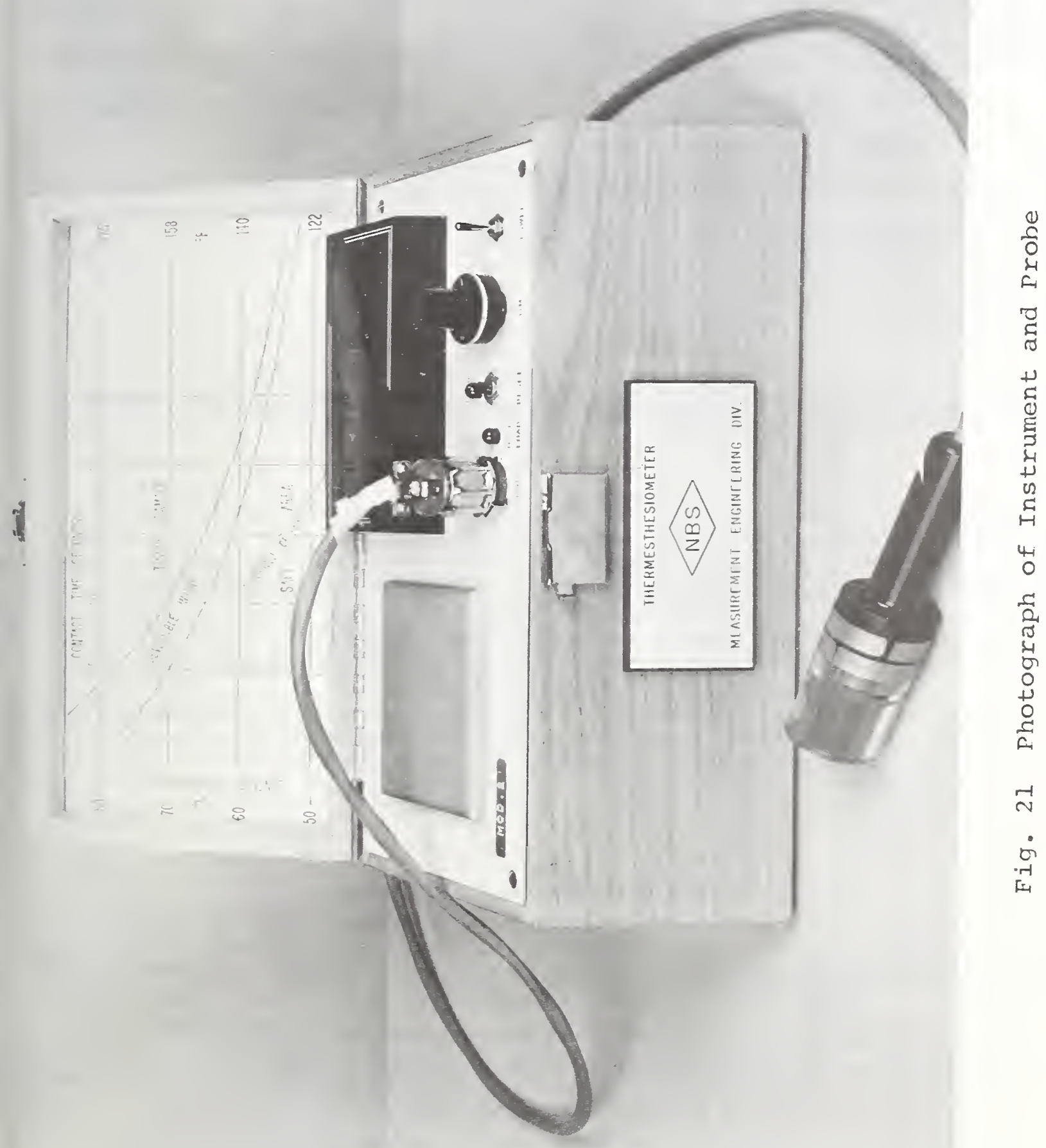


NBS-114A (REV, 7-73)

\begin{tabular}{|c|c|c|c|}
\hline $\begin{array}{l}\text { U.S. DEPT. OF COMM. } \\
\text { BIBLIOGRAPHIC DATA } \\
\text { SHEET }\end{array}$ & $\begin{array}{l}\text { 1. PUBL.I ATION OR REPORT NO. } \\
\text { NBS TN-816 }\end{array}$ & $\begin{array}{l}\text { 2. Gov't Accession } \\
\text { No. }\end{array}$ & 3. Recipient's Acecession No. \\
\hline \multirow{2}{*}{\multicolumn{3}{|c|}{$\begin{array}{l}\text { 4. TITLE AND SUBTITLE: } \\
\text { ENGINEERING AND CONSTRUCTION MANUAL FOR AN INSTRUMENT } \\
\text { TO MAKE BURN HAZARD NEASUREMENTS IN CONSUMER PRODUCTS }\end{array}$}} & $\begin{array}{l}\text { 5. Publication Date } \\
\text { Pebruary } 1974\end{array}$ \\
\hline & & & 6. Performing Organization Code \\
\hline \multicolumn{3}{|c|}{ 7. AUTHOR(S) Louis A. Marzetta } & 8. Performing Organ. Report No. \\
\hline \multirow{2}{*}{\multicolumn{3}{|c|}{$\begin{array}{l}\text { 9. PERFORMING ORGANIZATION NAME ANI) ADDRESS } \\
\qquad \begin{array}{l}\text { NATIONAL BUREAU OF STANDARDS } \\
\text { DEPARTMENT OF COMMERCE } \\
\text { WASHINGTON, D.C. } 20234\end{array}\end{array}$}} & $\begin{array}{l}\text { 10. Project/Task/Work Unit No. } \\
4460141,4460503\end{array}$ \\
\hline & & & 11. Contract/Grant No. \\
\hline \multirow{2}{*}{\multicolumn{3}{|c|}{$\begin{array}{l}\text { 12. Sponsoring Organization Name and Complete Address (Street, City, } \\
\text { Consumer Product Safety Commission } \\
\text { Washington, D. C. } 20016\end{array}$}} & $\begin{array}{l}\text { 13. Type of Report \& Period } \\
\text { Covered } \\
\text { Final }\end{array}$ \\
\hline & & & 14. Sponsoring Agency Code \\
\hline
\end{tabular}

16. ABSTRACT (A 200-word or less factual summary of most significant information. If document includes a significant bibliography or literature survey, mention it here.)

Surface temperature measurement alone is insufficient to establish the hazard of human contact with a hot or cold object. A metal surface is more likely to cause thermal injury than a plastic surface at the same temperature. An instrument equipped with a measuring probe has been developed for indicating the tissue temperature that would be experienced if human contact were made with the hot surface in question. The correct value of interface contact temperature can be read for a selected contact time without knowing the composition or temperature of the heated material under test.

A detailed set of instructions and drawings for assisting in the construction of the device is included in the manual. Several test procedures are described for use in checking the performance of the measuring probe and instrument.

17. KEY WORDS (six to twelve entries; alphabetical order; capitalize only the first letter of the first key word unless a proper name; separated by semicolons)

Consumer products; contact temperature; thermesthesiometer; thermometry.

\begin{tabular}{|c|c|c|}
\hline $\begin{array}{l}\text { 18. AVAILABILITY }[\mathrm{X} \text { Unlimited } \\
\square \text { For Official Distribution. Do Not Release to NTIS }\end{array}$ & $\begin{array}{l}\text { 19. SECURITY CLASS } \\
\text { (THIS REPURT) } \\
\text { UNCL ASSIFIED }\end{array}$ & $\begin{array}{l}\text { 21. NO. OF PAGES } \\
48\end{array}$ \\
\hline $\begin{array}{l}\text { Order From Sup. of Doc., U.S. Government Printing Office } \\
\text { Washington, D.C. } 20402, \text { SD Cat. No.C13 }\end{array}$ & $\begin{array}{l}\text { 20. SECURITY CLASS } \\
\text { (THIS PAGE) }\end{array}$ & 22. Price \\
\hline $\begin{array}{l}{[\text { Order From National Technical Information Service (NTIS) }} \\
\text { Springfield, Virginia } 22151\end{array}$ & UNCLASSIFIED & \\
\hline
\end{tabular}


PERIODICALS

JOURNAL OF RESEARCH reports National Burcau of Standards research and development in physics, mathematics, and chemistry. Comprehensive scientific papers give complete details of the work, including laboratory data, experimental procedures, and theoretical and mathematical analyses. Illustrated with photographs, drawings, and charts. Includes listings of other NBS papers as issued.

Published in two sections, available separately:

\section{- Physics and Chemistry (Section A)}

Papers of interest primarily to scientists working in these fields. This section covers a broad range of physical and chemical research, with major emphasis on standards of physical measurement, fundamental constants, and properties of matter. Issued six times a year. Annual subscription: Domestic, $\$ 17.00$; Foreign, \$21.25.

\section{- Mathematical Sciences (Section B)}

Studies and compilations designed mainly for the mathematician and theoretical physicist. Topics in mathematical statistics, theory of experiment design, numerical analysis, theoretical physics and chemistry, logical design and programming of computers and computer systems. Short numerical tables. Issued quarterly. Annual subscription: Domestic, $\$ 9.00$; Foreign, $\$ 11.25$.

\section{DIMENSIONS, NBS}

The best single source of information concerning the Bureau's measurement, research, developmental, cooperative, and publication activities, this monthly publication is designed for the layman and also for the industry-oriented individual whose daily work involves intimate contact with science and technology - for engineers, chemists, physicists, research managers, product-development managers, and company executives. Annual subscription: Domestic, $\$ 6.50$; Foreign, $\$ 8.25$.

\section{NOKPERIODICALS}

Applied Mathematics Series. Mathematical tables, manuals, and studies.

Building Science Series. Research results, test methods, and performance criteria of building materials, components, systems, and structures.

Handbooks. Recommended codes of engineering and industrial practice (including safety codes) developed in cooperation with interested industries, professional organizations, and regulatory bodies.

Special Publications. Proceedings of NBS conferences, bibliographies, annual reports, wall charts, pamphlets, etc.

Monographs. Major contributions to the technical literature on various subjects related to the Bureau's scientific and technical activities.

National Standard Reference Data Series. NSRDS provides quantitative data on the physical and chemical properties of materials, compiled from the world's literature and critically evaluated.

Product Standards. Provide requirements for sizes, types, quality, and methods for testing various industrial products. These standards are developed cooperatively with interested Government and industry groups and provide the basis for common understanding of product characteristics for both buyers and sellers. Their use is voluntary.

Technical Notes. This series consists of communications and reports (covering both other-agency and NBS-sponsored work) of limited or transitory interest.

Federal Information Processing Standards Publications. This series is the official publication within the Federal Government for information on standards adopted and promulgated under the Public Law 89-306, and Bureau of the Budget Circular A-86 entitled, Standardization of Data F.lements and Codes in Data Systems.

Consumer Information Series. Practical information, based on NBS research and experience, covering areas of interest to the consumer. Easily understandable language and illustrations provide useful background knowledge for shopping in today's technological marketplace.

\section{BIBLIOGRAPHIC SUBSCRIPTION SERVICES}

The following current-awareness and literature-survey bibliographies are issued periodically by the Bureau:

Cryogenic Data Center Current Awareness Service (Publications and Reports of Interest in Cryogenics). A literature survey issued weekly. Annual subscription: Domestic, $\$ 20.00$; foreign, $\$ 25.00$.

Liquefied Natural Gas. A literature survey issued quarterly. Annual subscription: $\$ 20.00$.

Superconducting Devices and Materials. A literature survey issued quarterly. Annual subscription: $\$ 20.00$. Send subscription orders and remittances for the preceding bibliographic services to the U.S. Department of Commerce, National Technical Information Service, Springfield, Va. 22151.

Electromagnetic Metrology Current Awareness Service (Abstracts of Selected Articles on Measurement Techniques and Standards of Electromagnetic Quantities from D-C to Millimeter-Wave Frequencies). Issued monthly. Annual subscription: $\$ 100.00$ (Special rates for multi-subscriptions). Send subscription order and remittance to the Electromagnetic Metrology Information Center, Electromagnetics Division, National Bureau of Standards, Boulder, Colo. 80302.

Order NBS publications (except Bibliographic Subscription Services) from: Supcrintendent of Documents, Government Printing Office, Washington, D.C. 20402. 
U.S. DEPARTMENT OF COMMERCE

National Bureau of Standards

Washington, D.C. 20234

OFFICIAL BUSINESS

U.S. OEPARTMENT OF COMMERCE

$C O M=235$

Penalty for Private Use, $\$ 300$ 